\title{
Ozone deposition into a boreal forest over a decade of observations: evaluating deposition partitioning and driving variables
}

\author{
Ü. Rannik ${ }^{1}$, N. Altimir ${ }^{2,3}$, I. Mammarella ${ }^{1}$, J. Bäck ${ }^{1,3}$, J. Rinne ${ }^{1}$, T. M. Ruuskanen ${ }^{1}$, P. Hari ${ }^{3}$, T. Vesala ${ }^{1}$, and \\ M. Kulmala ${ }^{1}$ \\ ${ }^{1}$ Department of Physics, P.O. Box 48, 00014 University of Helsinki, Finland \\ ${ }^{2}$ Forest Sciences Centre of Catalonia, 25280 Solsona, Spain \\ ${ }^{3}$ Department of Forest Ecology, P.O. Box 27, 00014 University of Helsinki, Finland
}

Correspondence to: Ü. Rannik (ullar.rannik@heuristica.ee)

Received: 28 April 2012 - Published in Atmos. Chem. Phys. Discuss.: 22 May 2012

Revised: 11 October 2012 - Accepted: 10 December 2012 - Published: 21 December 2012

\begin{abstract}
This study scrutinizes a decade-long series of ozone deposition measurements in a boreal forest in search for the signature and relevance of the different deposition processes. The canopy-level ozone flux measurements were analysed for deposition characteristics and partitioning into stomatal and non-stomatal fractions, with the main focus on growing season day-time data. Ten years of measurements enabled the analysis of ozone deposition variation at different time-scales, including daily to inter-annual variation as well as the dependence on environmental variables and concentration of biogenic volatile organic compounds (BVOCs). Stomatal deposition was estimated by using multi-layer canopy dispersion and optimal stomatal control modelling from simultaneous carbon dioxide and water vapour flux measurements, non-stomatal was inferred as residual. Also, utilising the big-leaf assumption stomatal conductance was inferred from water vapour fluxes for dry canopy conditions. The total ozone deposition was highest during the peak growing season $\left(4 \mathrm{~mm} \mathrm{~s}^{-1}\right)$ and lowest during winter dormancy $\left(1 \mathrm{~mm} \mathrm{~s}^{-1}\right)$. During the course of the growing season the fraction of the non-stomatal deposition of ozone was determined to vary from 26 to $44 \%$ during day time, increasing from the start of the season until the end of the growing season. By using multi-variate analysis it was determined that day-time total ozone deposition was mainly driven by photosynthetic capacity of the canopy, vapour pressure deficit (VPD), photosynthetically active radiation and monoterpene concentration. The multi-variate linear model explained the high portion of ozone deposition variance on daily average level $\left(R^{2}=0.79\right)$. The explanatory power of the multi-
\end{abstract}

variate model for ozone non-stomatal deposition was much lower $\left(R^{2}=0.38\right)$. The set of common environmental variables and terpene concentrations used in multivariate analysis were able to predict the observed average seasonal variation in total and non-stomatal deposition but failed to explain the inter-annual differences, suggesting that some still unknown mechanisms might be involved in determining the inter-annual variability. Model calculation was performed to evaluate the potential sink strength of the chemical reactions of ozone with sesquiterpenes in the canopy air space, which revealed that sesquiterpenes in typical amounts at the site were unlikely to cause significant ozone loss in canopy air space. The results clearly showed the importance of several non-stomatal removal mechanisms. Unknown chemical compounds or processes correlating with monoterpene concentrations, including potentially reactions at the surfaces, contribute to non-stomatal sink term.

\section{Introduction}

The carbon and water exchange of the ecosystems has been monitored and analysed across geographical locations and different ecosystem types over a long period with the use of micrometeorological stations (e.g., Goulden et al., 1996; Lindroth et al., 1998; Valentini et al., 2000). Similar results/reports on long-term measurement of ozone fluxes at the ecosystem level are rather limited (Zhang et al., 2002; Turnispeed et al., 2009; Fares et al., 2010). Nevertheless, extensive ozone deposition studies over different ecosystems 
have been performed in order to understand deposition mechanisms and possible harmful effect on ecosystems (e.g., Fowler et al., 2001; Lamaud et al., 2002; Goldstein et al., 2004; Holzinger et al., 2005, 2006; Altimir et al., 2006; Mészáros et al., 2009; Lamaud et al., 2009; Coyle et al., 2009).

Whereas the biotic control through stomatal uptake is better understood, a major knowledge gap is (still) the behaviour of the so-called non-stomatal deposition (Erisman et al., 2005; Wesley and Hicks, 2000; Fowler et al., 2009). Several mechanisms have been proposed to play a role in creating the non-stomatal deposition. Surface wetness modulates the deposition, usually enhancing it, as it has been showed in many works (summarised in Massman, 2004; Altimir et al., 2006). Fowler et al. (2001) propose thermal decomposition as another mechanism, which in Coyle (2005) was suggested to be the main sink on dry surfaces. Homogeneous and heterogeneous reactions with organics or other reactive compounds have also been considered. Many studies emphasize the role of gas-phase chemical reactions on ozone deposition. Several papers addressing the ozone deposition over pine forests (Goldstein et al., 2004; Holzinger et al., 2005, 2006) revealed the role of the chemical reactions with BVOC-s in ozone removal. Kurpius and Goldstein (2003) noted that lifetimes of many reactive terpenes can be less than a minute and significant part of ozone deposition into ecosystem was due to chemical loss in the canopy. Holzinger et al. (2006) identified connection between monoterpene flux and nonstomatal ozone flux, further suggesting that large amounts of other substances reacting with ozone are released causing the observed correlation. Goldstein et al. (2004) studied the monoterpene emission and ozone uptake over thinning performed in California pine forest. They observed simultaneous enhancement of monoterpene emission and ozone uptake and suggested that this simultaneous enhancement provided strong evidence that ozone reacted with unmeasured BVOC-s.

The present knowledge on ozone deposition is that there are various mechanisms removing the ozone at the canopyair interface, controlled both by biotic and abiotic processes and simultaneously modulated by the environmental factors. This means that in addition to the characteristics of the vegetation cover, the prevailing environmental factors will be determinant in promoting a particular pathway to ozone deposition. It is, then, expected that at different locations or/and under different climate regimes the ozone deposition might be dominated by a particular set of ozone removal processes. For example, Stella et al. (2011) have modelled ozone deposition into crop throughout the growing season by considering soil resistance and humidity dependent cuticular and stomatal resistances with high degree of explanatory power for three measurement sites. In turn Fares et al. (2010) observe that non-stomatal deposition into ponderosa pine forest is the dominant process of ozone removal, likely due to the ecosystem's release of VOCs that rapidly react with ozone.
Therefore, the control of ozone deposition likely differs between sites and between years and seasons within one site.

The ozone fluxes over the boreal pine forest in Hyytiälä, Southern Finland have been measured since 2001. Altimir et al. $(2004,2006)$ studied the ozone removal at the site by using the shoot-level chamber as well as the canopy level eddy covariance measurements. The findings indicated that ozone deposition was strongly affected by the humidity conditions of surfaces and non-stomatal deposition contributed from 25 to $50 \%$ of total deposition in dry conditions and from 50 to $60 \%$ in moist conditions. Rannik et al. (2009) studied the night-time ozone deposition at the same forest site and found that it was invariant with the turbulence intensity suggesting that available time for chemical reactions during the turbulent transport inside canopy did not affect the ozone sink strength.

Overall ozone deposition can only be understood as the overlap of different scavenging phenomena that in turn results in the different temporal patterns. The occurrence and relevance of these various deposition processes can be addressed with long-term measurements that cover the whole range of environmental conditions at the site. In addition, long-term measurements enable to reduce the uncertainty in canopy level measurements and obtain confidence in ozone deposition characteristics. The current study further utilises long-term ozone deposition measurements performed at the boreal forest site in Hyytiälä to determine ozone deposition and its partitioning into stomatal and non-stomatal components, and in particular the potential role of BVOC ozonolysis. Therefore, the analysis presented here focuses primarily on day-time data during the growing season, presenting also shortly the night-time and dormant season deposition statistics. Multi-layer modelling approach using the optimal stomatal model was combined with inverse estimation of stomatal model parameters from carbon dioxide and water flux measurements in order to estimate the stomatal ozone deposition component. The study scrutinizes a long time series of ozone deposition measurements in order to investigate the signature and the relevance of different deposition processes. The measured and modelled fluxes are decomposed into bulk canopy level conductances to (a) present ozone deposition statistics based on a very long time series, (b) evaluate diurnal, seasonal and inter annual variability of total and non-stomatal conductance employing multi-variate analysis techniques and (c) identify environmental variables and concentrations of biogenic volatile organic compounds driving ozone deposition in order to assess the processes responsible for ozone removal at the site.

\section{Materials and methods}

\subsection{Site and measurement station}

The SMEAR II (Station for Measuring Forest EcosystemAtmosphere Relations) field measurement station is 
located in Hyytiälä, Southern Finland $\left(61^{\circ} 51^{\prime} \mathrm{N}, 24^{\circ} 17^{\prime} \mathrm{E}\right.$, 181 ma.s.l.). The station is located in the area covered mainly by pine-dominated forests, with the homogeneous Scots pine stand, established in 1962, around the tower for about $200 \mathrm{~m}$ to all directions, extending to the North about $1 \mathrm{~km}$. The dominant height of the stand near the measurement tower was about 14-18 m from 2000 till 2010. The forest was manually thinned between January and March 2002 over an area of 4.3 ha around the measurement tower according to general commercial forest management procedures. During thinning about $26 \%$ of the basal area (determined at the height of 1.3) was removed and the all-sided leaf area index (LAI) in the canopy of the thinned areas dropped from 8 to 6 (Vesala et al., 2005). More detailed description of the station and the measurements can be found in Hari and Kulmala (2005).

\subsection{Measurements}

\subsubsection{Measurement of turbulent fluxes}

Turbulent fluxes of momentum, heat, $\mathrm{CO}_{2}, \mathrm{H}_{2} \mathrm{O}$ and $\mathrm{O}_{3}$ were measured by means of the eddy covariance technique. The system, located at $23 \mathrm{~m}$ height above the ground on the top of a scaffolding tower, included an ultrasonic anemometer (Solent Research HS1199, Gill Ltd., Lymington, Hampshire, England) to measure the three wind velocity components and the sonic temperature, a closed-path infrared gas analyser (LI-6262, LiCor Inc., Lincoln, NE, USA) that measured the $\mathrm{CO}_{2}$ and $\mathrm{H}_{2} \mathrm{O}$ concentrations, and a fast response chemiluminescence gas analyzer for the ozone concentration (LOZ3 Ozone analyzer, Unisearch Associates Inc., Concord, Ontario, Canada). The calibration and maintenance procedures of the $\mathrm{O}_{3}$ analyzer were described in detail by Keronen et al. (2003). The data were sampled at $21 \mathrm{~Hz}$ and a 2-D rotation of sonic anemometer wind components (McMillen et al., 1998) and filtering to eliminate spikes were performed according to standard methods (Vickers and Mahrt, 1997). The high-frequency flux attenuation was corrected by using empirical transfer functions and co-spectral transfer characteristics (Keronen et al., 2003; Rannik et al., 2004; Mammarella et al., 2009).

\subsubsection{Radiation and humidity measurements}

At SMEAR II, mean profiles of $\mathrm{O}_{3}, \mathrm{CO}_{2}, \mathrm{H}_{2} \mathrm{O}, \mathrm{NO}$ and $\mathrm{NO}_{\mathrm{x}}$ concentrations, wind speed, air temperature $\left(T_{\mathrm{a}}\right)$ and relative humidity (RH) were continuously measured at 4.2, 8.4, 16.8, $33.6,67 \mathrm{~m}$ at a $72 \mathrm{~m}$ tall tower and described elsewhere (Hari and Kulmala, 2005; Rannik et al., 2004). This main tower was located ca. $35 \mathrm{~m}$ west from the ozone scaffolding flux system tower.

Global radiation $\left(R_{\mathrm{g}}\right)$ was measured by Reeman TP 3 pyranometers (Astrodata, Estonia) and photosynthetic photon flux density (PAR) by LI-190SZ quantum sensor (LiCor
Inc., Lincoln, NE, USA) at $22 \mathrm{~m}$ height on the top of the scaffold flux tower.

\subsubsection{BVOC measurements}

Concentrations of VOCs were measured by PTR-MS (Ionicon Analytic $\mathrm{GmbH}$, Austria) from scaffolding tower at 4, 14, $22 \mathrm{~m}$ during 2006-2009 (Taipale et al., 2008) and in 2010 from 4.2, 8.4, 16.8, 33.6, $67 \mathrm{~m}$ at the $72 \mathrm{~m}$ tall tower. Air was continuously sampled trough heated Teflon lines from each of the heights and measured in turn. The continuous online measurements were corrected for the background measured from purified air (Parker Hannifin Corp., ChromGas Zero Air Generator) every second or third hour. The instrument was calibrated for monoterpenes every second week with $\alpha$ pinene in a gas standard (Apel-Riemer Environment, Inc.) that was also the base for the estimation of the sesquiterpenes.

\subsubsection{Soil temperature and water content}

Humus and soil temperatures were measured by silicon temperature sensors (Phillips KTY81-110) at $2 \mathrm{~cm}$ (humus) and between 5 and $25 \mathrm{~cm}$ (mineral soil) depths. Soil volumetric water content was measured with time-domain reflectrometry (TDR) by using Tektronix $1502 \mathrm{C}$ cable radar (Tektronix Inc., Redmond, USA) between 1998 and 2004 and from 2005 onwards with TDR100 (Campbell Scientific Inc., Logan, UT) connected to a data logger (Campbell 21X, Campbell Scientific Ltd., Leics., UK) via multiplexers (SDMX50, Campbell Scientific Ltd., Leics., UK). TDR-probes consisted of two stainless steel rods (175 mm long, $5 \mathrm{~mm}$ in diameter). The probes were connected with a coaxial cable (type RG 58) to the multiplexers. 64 TDR probes were installed and they were distributed in different soil horizons of the 7 soil pits and in the soil adjacent to the weir. The TDR measurements were done at hourly intervals throughout the year.

\subsection{Methods of analysis}

\subsubsection{Multi-layer modeling of stomatal deposition}

Multi-layer approach combining the turbulent exchange model based on the K-theory and optimal stomatal conductance model (Appendix A) combined with the radiation attenuation model inside canopy (Appendix B) was used to model the canopy stomatal exchange of carbon dioxide, water vapour and ozone, similarly to Altimir et al. (2006). The intercellular concentration of water was assumed equal to the saturated water vapour concentration at leaf temperature, see Appendix A, whereas for ozone was taken equal to zero.

The calculation of the optimal stomatal model parameters from canopy level carbon dioxide and water flux measurements was done by least square minimisation of measured vs. modelled fluxes over two distinct time scales following the idea by Thum et al. (2007): photosynthetic capacity 
parameter $\alpha$ was obtained with weekly intervals and the cost of water for carbon assimilation $\lambda$ and the saturation parameter of photosynthesis $\gamma$ were obtained over entire growing season of each year. Thus the numerical optimisation was performed for parameters for growing season with embedded optimisation at weekly interval for $\alpha$. Variation in photosynthetic capacity parameter $\alpha$ was supposed to incorporate other effects possibly affecting stomatal regulation, including the variation in leaf area during the course of growing season and also the thinning effect described in Sect. 2.1. In general, variation of $\lambda$ and $\gamma$ during the growing season could occur in case of significant change of soil water availability. However, the episodic variation in plant's water use efficiency and/or saturation of photosynthesis at high irradiance values can be included in variation of parameter $\alpha$ without loss in predicting ability of the optimal stomatal model. Thus the output of optimisation was the yearly values of $\lambda$ (varying from 0.0026 to $0.0056 \mathrm{~g} \mathrm{CO}_{2}\left(\mathrm{~g} \mathrm{H}_{2} \mathrm{O}\right)^{-1}$ in different years) and $\gamma$ (varying between 1865 and $2843 \mu \mathrm{mol} \mathrm{m}^{-2} \mathrm{~s}^{-1}$ ) and weekly values of $\alpha$ (see Fig. 2 below for seasonal variation).

The stomatal conductance inferred from optimal model (Appendix A) was subsequently used to predict also ozone stomatal deposition by accounting for difference in molecular diffusivity.

\subsubsection{Bulk canopy conductances}

Total turbulent flux consisting of stomatal and non-stomatal deposition components, $F=F^{\mathrm{S}}+F^{\mathrm{NS}}$, defines the bulk conductances at canopy top respectively as

$G=G^{\mathrm{S}}+G^{\mathrm{NS}}$,

where for the purpose of analysis in this paper the conductances are defined with respect to concentrations at the canopy height $C(h)$ as $G=-\frac{F}{C(h)}$. Thus the stomatal bulk conductance $G^{\mathrm{NS}}$ is not purely the stomatal conductance but merges also the quasi-laminar leaf boundary layer transfer pathway, which, under most conditions is less important in total transfer pathway and does not affect the interpretation of results.

The non-stomatal deposition conductance $G^{\mathrm{NS}}$ that we consider in this study combines sinks with arbitrary location inside forest, i.e., scavenging acting inside canopy air space (homogeneous chemical reactions) and/or removal at foliage including also ground vegetation or soil surface (homogeneous and hetereogeneous reactions). In practice the non-stomatal conductance was inferred from the total ozone conductance as the residual $G^{\mathrm{NS}}=G-G^{\mathrm{S}}$, where the stomatal conductance for ozone was calculated from the flux at the canopy top $F_{\mathrm{O}_{3}}(h)$ as obtained from the semi-empirical multi-layer model described in Appendices A as

$G_{\mathrm{O}_{3}}^{\mathrm{S}}=-\frac{F_{\mathrm{O}_{3}}(h)}{C_{\mathrm{O}_{3}}(h)}$.
The optimal stomatal model performs only during day-time, however it can be applied to all humidity conditions.

Stomatal conductance applicable to water vapour was also inferred from the water vapour flux $E$ measurements under dry conditions when transpiration is assumed to be the major component in canopy level flux $E$. In this case, the bulk canopy level conductance for water vapour is given by

$G_{\mathrm{H}_{2} \mathrm{O}}^{\mathrm{T}}=\frac{E}{\left[\mathrm{H}_{2} \mathrm{O}\right]_{\mathrm{sat}}-\left[\mathrm{H}_{2} \mathrm{O}\right]}$.

where $\left[\mathrm{H}_{2} \mathrm{O}\right]$ denotes the water vapour concentration in the air and $\left[\mathrm{H}_{2} \mathrm{O}\right]_{\text {sat }}$ the respective intercellular value, assumed equal to the saturated water vapour content at needle temperature (see Appendix A). The stomatal conductance inferred from water vapour flux measurements can be converted to ozone stomatal conductance by using the ratio of molecular diffusivities, defined as $G_{\mathrm{O}_{3}}^{\mathrm{T}}=\frac{D_{\mathrm{O}_{3}}}{D_{\mathrm{H}_{2} \mathrm{O}}} G_{\mathrm{H}_{2} \mathrm{O}}^{\mathrm{T}}$, where $D_{\mathrm{O}_{3}}$ and $D_{\mathrm{H}_{2} \mathrm{O}}$ denote molecular diffusivities of ozone and water, respectively. Such a similarity for sources holds when evaporation from surfaces is negligible i.e., under dry conditions and when non-stomatal ozone uptake is marginal.

The canopy level stomatal conductance values obtained from water fluxes are applicable only when the foliage surface is dry. In the current study, the canopy level stomatal conductance obtained from water fluxes $\left(G_{\mathrm{H}_{2} \mathrm{O}}^{\mathrm{T}}\right)$ was used to infer the stomatal conductance when $\mathrm{RH}<70 \%$. The $G_{\mathrm{H}_{2} \mathrm{O}}^{\mathrm{T}}$ also neglects the soil evaporation, which is expected to be small. However, the stomatal and non-stomatal conductances as obtained from the optimal stomatal model were analysed throughout the growing season in day-time and for all humidity conditions.

\subsubsection{Ozone chemical degradation modelling}

For ozone also chemical degradation in canopy air space was considered due to reactions with sesquiterpenes, emitted by the forest canopy. The chemical degradation of ozone was assumed to occur with $\beta$-caryophyllene, being used as the surrogate for sesquiterpenes. It is one of the most likely ozone sink candidates in canopy air space due to the relatively fast reaction rate with ozone. However, its significance in ozone removal depends on the abundance of the sesquiterpenes in the air, which is related to the emission rates as well as to the turbulent transport time scale. The chemical reactions with monoterpenes were not included in the model analysis due to slow reactivity with ozone, instead an order of magnitude analysis of their potential role in ozone destruction is presented in Sect. 4.

For $\beta$-caryophyllene temperature dependent emission was directly modelled according to Guenther (1993) and Hakola et al. (2006), see Appendix C. Needle dry mass $0.54 \mathrm{~kg} \mathrm{~m}^{-2}$ of ground surface area was assumed as in earlier studies for the given site (Ilvesniemi and Liu, 2001; Rinne et al., 2007). The emission factor $\varepsilon$ was assumed to take two different values in scenario evaluations: 385 and $10000 \mathrm{ng} \mathrm{g}^{-1}(\mathrm{dw}) \mathrm{h}^{-1}$. 

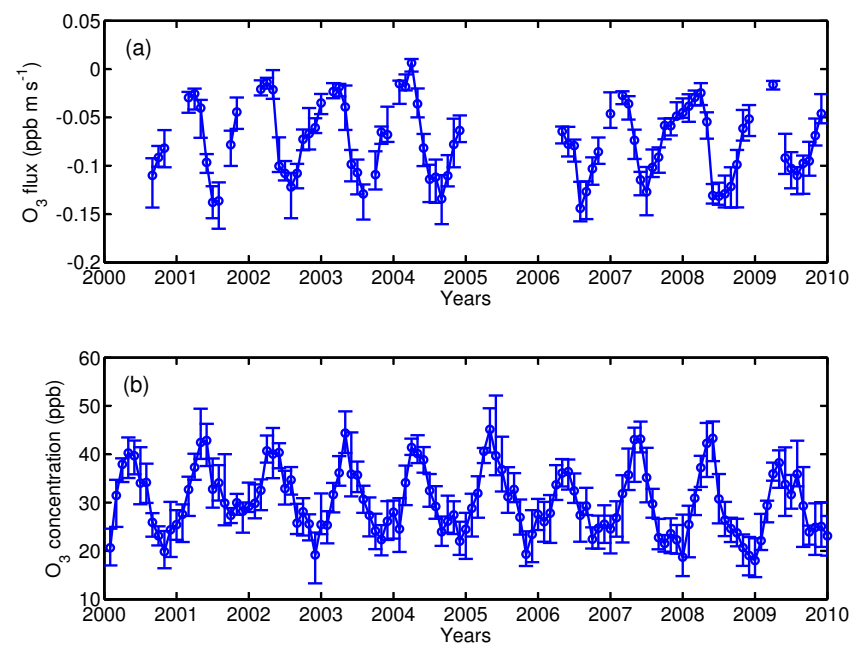

Fig. 1. Ten years time series of $\mathrm{O}_{3}$ fluxes (a) and concentrations (b). Monthly medians (circles) and quartiles of daily average fluxes and concentrations are presented.

The first value describes well the observations by Hakola et al. (2006) performed at the same site and the second value was chosen as significantly higher value for sensitivity test.

In order to solve concentration and flux profiles simultaneously for ozone and $\beta$-caryophyllene, an iterative method was used over equally spaced vertical layers with the thickness $0.02 \mathrm{~h}$ all the way up to the atmospheric boundary layer (ABL) height. For vertical integration a numerically stable forward Eulerian scheme was combined with corrective Eulerian backward iteration at each level. The measured ozone concentration at the canopy top and zero $\beta$-caryophyllene flux assumption at the upper boundary of the simulation domain (all emitted quantity consumed by ozone chemistry inside model domain under steady-state conditions) were superimposed as the boundary conditions. Since no sensitivity of the results on the ABL height was observed from the model runs the ABL height was set for simplicity to $300 \mathrm{~m}$.

\section{Results}

The ozone fluxes used in the current study originate from the period from August 2001 till December 2010 (Fig. 1). In 2006 a longer measurement break occurred due to technical malfunctioning of the $\mathrm{O}_{3}$ analyzer starting in December 2005 and data from full 2006 were not available. The average flux data coverage for the remaining period, excluding 2006, was $66 \%$. The average fluxes as well as concentrations exhibit clear seasonal variation with highest deposition occurring in summer and lowest in winter seasons. It is important to note that the flux is driven by total conductance (i.e., stomatal and non-stomatal) and ambient concentration of ozone. The ozone concentration has also seasonal and diurnal variation.

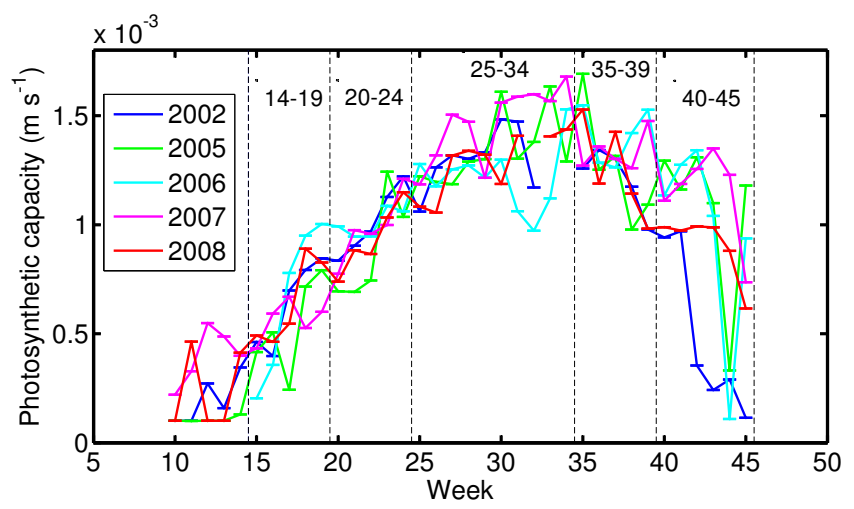

Fig. 2. Estimated photosynthetic capacity parameter $\alpha$ with a weekly interval for the selected years from 2001 till 2010, for daytime observations as defined by $h_{0}>10^{\circ}$.

The ozone uptake by forest canopy is expected to be a function of canopy photosynthetic capacity $\alpha$ through stomatal removal mechanism. The seasonal variability of canopy photosynthetic activity exhibits a continuous increase until approximately end of August. Following decline of the photosynthetic capacity is faster than increase (Fig. 2). The parameter accounts also for changes in LAI as the variation in leaf area was not directly included in the model. The parameter $\alpha$ exhibits similar behaviour in all years. Differences occur mainly during the beginning and end of growing seasons and also in 2006, when the decline of the values during weeks 30 to 34 indicates the impact of drought occurring at that year.

As parameter $\alpha$ incorporates all possible variation mechanisms affecting photosynthetic capacity at canopy level, it serves as the useful parameter to determine different periods during the growing season. Accordingly, the entire growing season was divided into five sub-periods for the analysis below including weeks 15-19, 20-24, 25-34, 35-39, 40-45. The overall period between weeks $15-45$ roughly coincides with the thermal growing season. Period 15-19 would be roughly the spring recovery, 20-24 cover the elongation period, 25-39 cover the thickening, 40-45 is the autumn decline and preparation for the winter dormancy. In addition, one period outside the growing season was considered consisting of the two sub-periods from weeks 1 to 14 and 45 to 52 , and covering the whole thermal winter and winter dormancy.

In addition to dividing data into sub-periods according to the growing season as defined above, the following averaging was used in data analysis: dependence on the environmental variables was analysed by utilising half-hour average data and the analysis was limited to the peak of the growing season within weeks 25-34 to limit the interference with seasonal variation; for the purpose of inter-annual and seasonal variability analysis diurnal (for multivariate analysis 

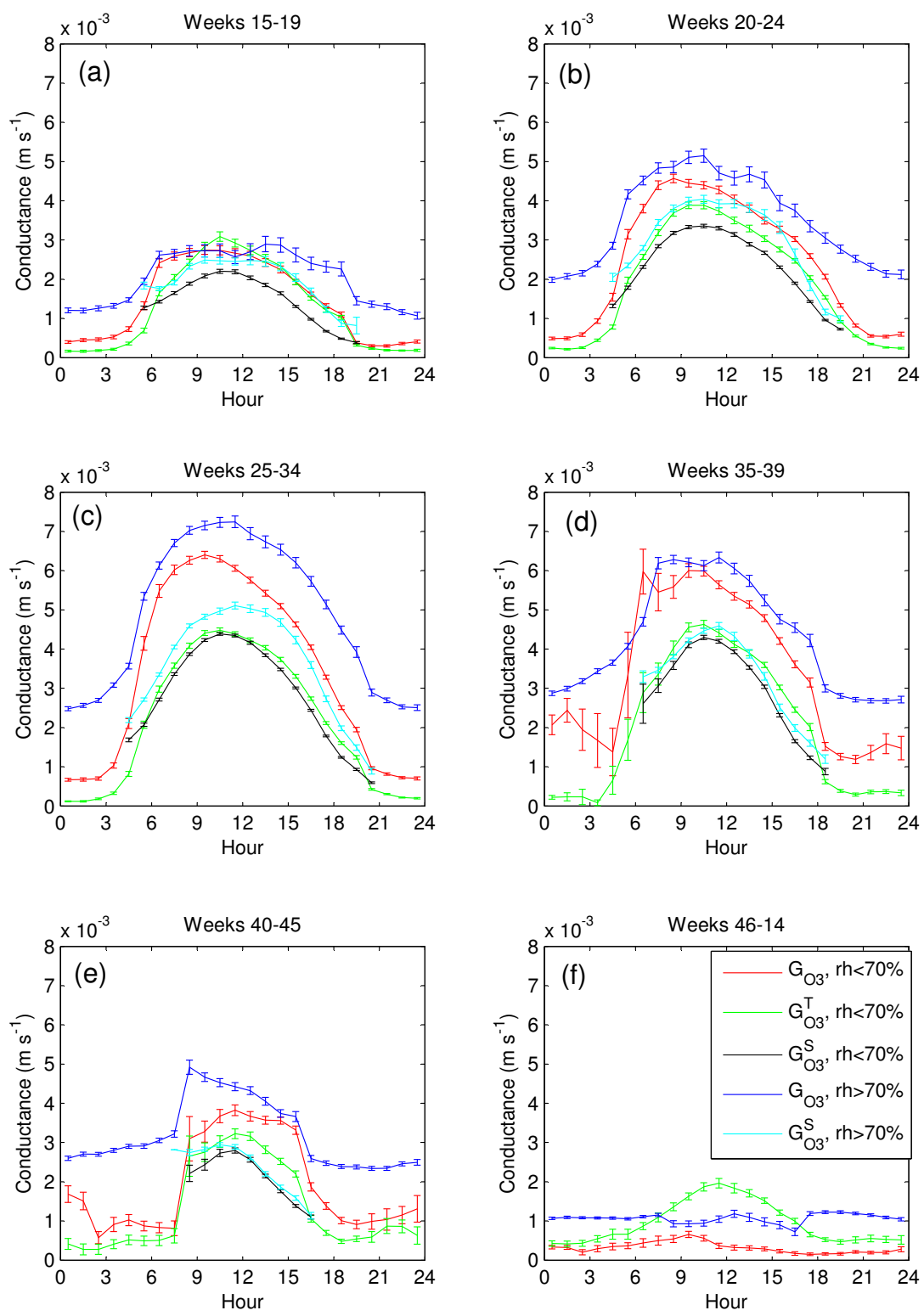

Fig. 3. Diurnal variation of conductances during different seasons (a) weeks 15-19, (b) weeks 20-24, (c) weeks 25-34, (d) weeks 35-39, (e) weeks 40-45, (f) weeks 46-52 and 1-14 for low and high RH conditions. $G_{\mathrm{O}_{3}}$ denotes total ozone and $G_{\mathrm{O}_{3}}^{\mathrm{S}}$ stomatal ozone conductances, and $G_{\mathrm{O}_{3}}^{\mathrm{T}}$ ozone stomatal conductance as inferred from water (transpiration) conductance. Values are hourly averages from data for all years during the given period, bars denote standard error.

purpose) and weekly averages (for graphical presentation purposes) were used.

Results are analysed in terms of conductances as defined in Sect. 2.3.2. The presented results are differentiated between day-time (elevation angle of Sun $>10^{\circ}$ ) and night-time (elevation angle of Sun $<0^{\circ}$ ) data. In addition, observations corresponding to very low turbulence often characterized by large random flux errors were excluded and only $30 \mathrm{~min}$ periods with $u_{*}>0.1 \mathrm{~m} \mathrm{~s}^{-1}$ have been used in this study.

\subsection{Diurnal variation of ozone deposition}

Stomatal ozone deposition is expected to have significant diurnal as well as seasonal variation. To separate these scales, diurnal variation of conductances was calculated for different seasons according to weekly intervals as defined previously.

Figure 3 presents the total $\left(G_{\mathrm{O}_{3}}\right)$ and stomatal $\left(G_{\mathrm{O}_{3}}^{\mathrm{S}}\right.$ as inferred from optimal stomatal model and $G_{\mathrm{O}_{3}}^{\mathrm{T}}$ as inferred from canopy level transpiration fluxes) conductance for different seasons, classified according to low and high $\mathrm{RH}$ values. Following the analysis by Altimir et al. (2006), a threshold value 

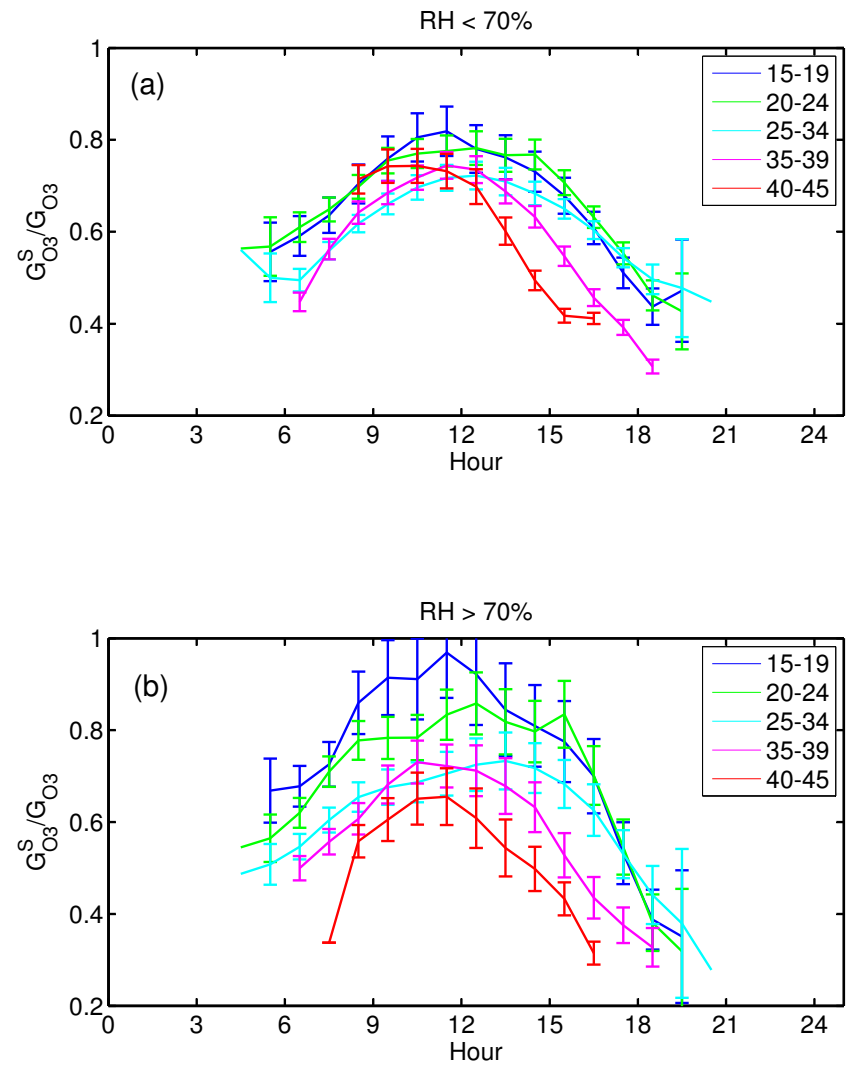

Fig. 4. Diurnal variation of the ratio of the average stomatal and total ozone conductances for $\mathrm{RH}<70 \%$ (a) and $\mathrm{RH}>70 \%$ (b). Bars denote standard error.

of $70 \%$ for RH was chosen to separate conditions with significant impact of surface moisture on ozone deposition. Also it was tested that the conductances $G_{\mathrm{O}_{3}}^{\mathrm{S}}$ as and $G_{\mathrm{O}_{3}}^{\mathrm{T}}$ where in very good correspondence at $\mathrm{RH}$ limiting interval from 65 to $70 \%$ (not shown here) for all periods except the spring recovery period (weeks 15-19), when snow thawing presumably has contributed to water fluxes and resulted in overestimation by $G_{\mathrm{O}_{3}}^{\mathrm{T}}$. The ozone deposition evolves during the growing season, being highest at mid-day and during the peak of the growing season period in weeks 25-34. Clearly the stomatal as well as the total ozone deposition is mainly driven by the course of stomatal opening during the day. However, the total $\mathrm{O}_{3}$ deposition exceeded that of stomatal significantly. Also the conductances under low relative humidity were smaller than under high relative humidity conditions.

Outside the growing season, starting from week 46 until week 14, no clear diurnal variation occurs. Also here $\mathrm{RH}$ is a variable enabling to separate higher and lower $\mathrm{O}_{3}$ deposition values.

It is of further interest how the ozone conductance partitions into stomatal and non-stomatal parts during day-time when values from the optimal stomatal model are available (Fig. 4). At mid-day the stomatal deposition accounts for highest fraction of $\mathrm{O}_{3}$ deposition up to $80 \%$. The fraction of stomatal deposition is reduced in early morning and late evening and accounts approximately for $50 \%$ of the total deposition. Corresponding variation in non-stomatal conductance exhibits higher absolute values in the morning and evening hours and minimum around mid-day (not shown). It is also evident that proportion into stomatal and non-stomatal parts is systematically different during different stages along the growing season and that the differences are amplified during more humid conditions ( $\mathrm{RH}>70 \%$ ).

To further quantify the average deposition characteristics, day-time and night-time average deposition values were calculated (Table 1). Day-time total $\mathrm{O}_{3}$ deposition increases during the course of the growing season and is highest when the photosynthetic capacity reaches peak values during weeks 25-34. However, while the stomatal deposition behaves in similar way, the non-stomatal fraction of $\mathrm{O}_{3}$ deposition increases through the growing season until its end. Similar trend is observed under low $(\mathrm{RH}<70 \%)$ and high (RH $>70 \%$ ) relative humidity conditions, but the total and stomatal deposition rates are higher under high humidity. From current data, the fraction of non-stomatal deposition does not show any clear difference under low and high RH during day-time.

At night $G_{\mathrm{O}_{3}}^{\mathrm{T}}$ is taken as the surrogate for the stomatal deposition. It is expected that ozone stomatal deposition is over-estimated by $G_{\mathrm{O}_{3}}^{\mathrm{T}}$ due to water flux originating from ground vegetation and soil, being not eliminated in $G_{\mathrm{O}_{3}}^{\mathrm{T}}$. This is supported also by the day-time observations, when $G_{\mathrm{O}_{3}}^{\mathrm{T}}$ systematically exceeds $G_{\mathrm{O}_{3}}^{\mathrm{S}}$ average values. Nevertheless, although the absolute value of night-time non-stomatal deposition cannot be reliably quantified, the increasing trend of non-stomatal $\mathrm{O}_{3}$ deposition along the growing season until the peak period is also clear at night (under low RH).

\subsection{Ozone deposition during peak of growing season}

\subsubsection{Day-time relation to environmental variables}

Environmental variables such as turbulence intensity, relative humidity and light intensity have been known to affect the stomatal and non-stomatal deposition. It is also evident that several environmental variables are intercorrelated. Friction velocity did not affect the stomatal and non-stomatal deposition in a systematic way (not shown). Furthermore, variation of total and non-stomatal conductance as a function of relative humidity $(\mathrm{RH})$, temperature and photosynthetically active radiation (PAR) was studied below. To avoid the influence of development of canopy photosynthetic capacity and other possible effects on deposition during the evolution in growing season, only data from the peak growing season period (weeks 25-34) are presented. Similar analysis was performed also for other periods (spring and autumn), but the results did not differ qualitatively. 
Table 1. Average values of ozone conductances $\left(\mathrm{mm} \mathrm{s}^{-1}\right)$ as classified according to the relative humidity, time of day and season. The non-stomatal conductance is given as a fraction $(\%)$ of the total conductance. W denotes week, $\mathrm{RH}$ relative humidity, $G_{\mathrm{O}_{3}}$ the total $\mathrm{O}_{3}$ conductance, and $G_{\mathrm{O}_{3}}^{\mathrm{S}}$ and $G_{\mathrm{O}_{3}}^{\mathrm{T}}$ the stomatal conductances as inferred from the optimal stomatal model and the canopy level transpiration fluxes, respectively.

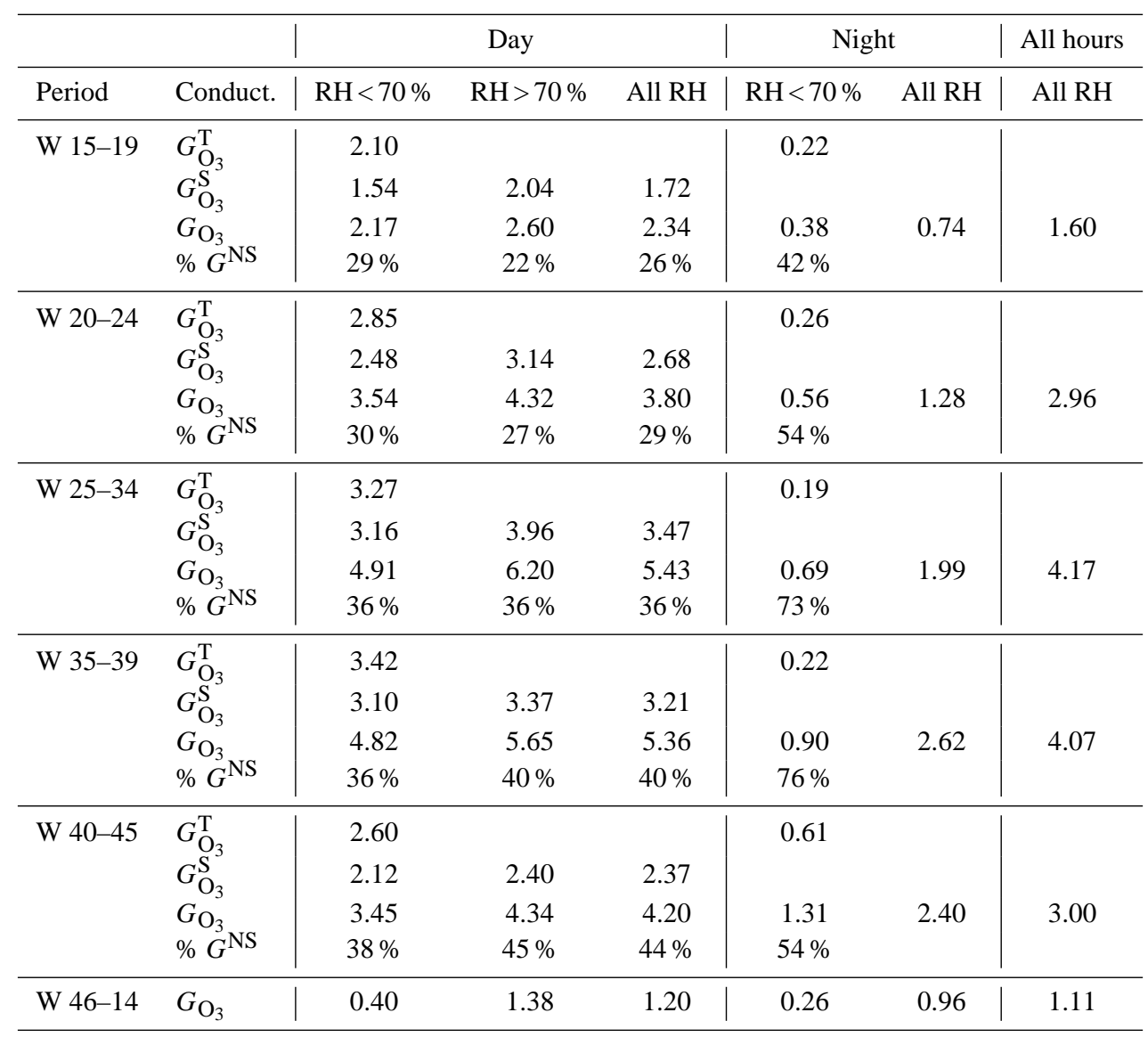

Relative humidity had a positive average impact on total as well as on non-stomatal $\mathrm{O}_{3}$ deposition. Figure 5a classifies conductance dependencies also according to the air temperature which enables to conclude that temperature itself does not have major impact on studied conductances or cannot be revealed due to the intercorrelation of environmental variables. As evident from Fig. 5b, high PAR conditions favour $\mathrm{O}_{3}$ total deposition, but does not affect the non-stomatal part.

The solar radiation can affect canopy $\mathrm{O}_{3}$ deposition by several indirect mechanisms. First, stomatal opening and conductance is a function of PAR. Also, abundance of many chemical compounds relevant to $\mathrm{O}_{3}$ chemistry has been related to PAR levels inside canopy (Gao et al., 1993; Guenther, 1997). According to Fig. 6, PAR has significant impact on total $\mathrm{O}_{3}$ deposition but the non-stomatal component is not affected on the average. As observed earlier, RH classification impacts also total ozone deposition. However, Fig. 6a indicates that classification into low and high RH has little impact on non-stomatal deposition apart from low PAR values, where more than two-fold difference occurs on the average.

\subsubsection{Night-time deposition}

The conductance inferred from water flux measurements $G_{\mathrm{O}_{3}}^{\mathrm{T}}$ was used as a surrogate to estimate stomatal deposition at night during dry periods only. The temperature has minor relation to total $\mathrm{O}_{3}$ deposition, also the impact is minor to non-stomatal deposition at low $\mathrm{RH}$ as determined from $G_{\mathrm{O}_{3}}^{\mathrm{T}}$ (Fig. 7a).

Clearest driver for night-time total ozone deposition is $\mathrm{RH}$, the impact from RH 40 to $100 \%$ being almost ten-fold (Fig. 7b). Note that this was obtained for the peak of the growing season period weeks 25-34 and was quantitatively different in other periods (not shown). Evidently the nighttime $\mathrm{O}_{3}$ deposition is much more affected by humidity conditions and total $\mathrm{O}_{3}$ conductance under close to saturating conditions can be almost as high as day-time conductance when majority of $\mathrm{O}_{3}$ deposits through stomatal pathway. $\mathrm{Re}$ garding seasonal variation, the night-time $\mathrm{O}_{3}$ deposition increases throughout the growing season and peaks prior to the end of the period (Table 1). 

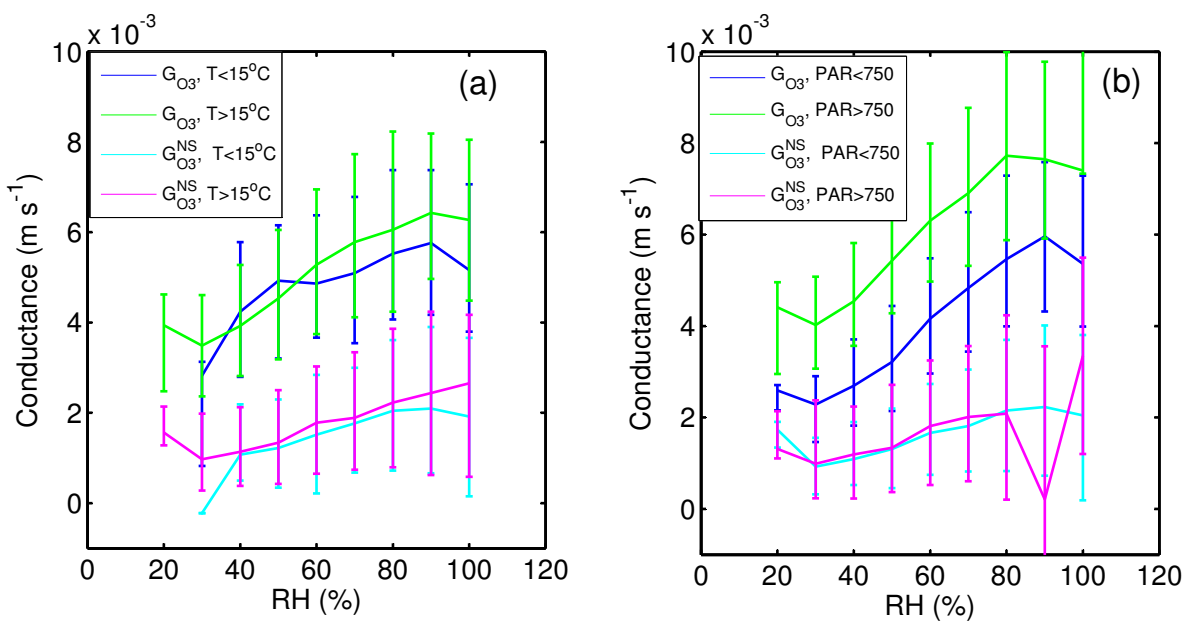

Fig. 5. Day-time (elevation angle of sun $>10^{\circ}$ ) ozone conductance as a function of RH during weeks $25-34.15^{\circ} \mathrm{C}$ and $750 \mu m o l \mathrm{~m}^{-2} \mathrm{~s}^{-1}$ were used as the values to separate high and low temperature (a) and PAR (b) conditions. Medians of 30 min average observations together with quartiles are presented.
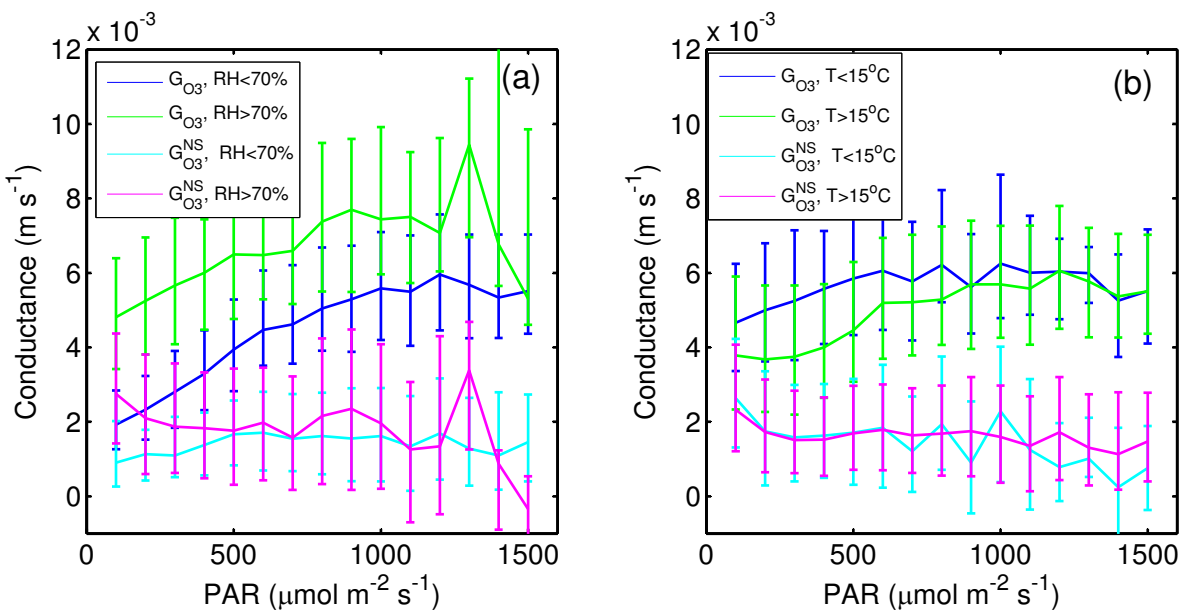

Fig. 6. Day-time (elevation angle of sun $>10^{\circ}$ ) ozone conductance as a function of PAR during the peak of the growing season weeks $25-34$. $70 \%$ and $15{ }^{\circ} \mathrm{C}$ were used as the values to separate high and low relative humidity (a) and temperature (b) conditions. Medians of 30 min average observations together with quartiles are presented.

\subsection{Seasonal and inter-annual variation}

A clear seasonal trend was observed in $\mathrm{O}_{3}$ total and nonstomatal conductances. It is also evident from Fig. 2 that canopy photosynthetic capacity exhibits the inter-annual variability. The biggest differences between years occur during the beginning and end of the growing seasons but also during the other periods due to specific weather conditions or yet unidentified reasons. This section focuses on the daytime average $\mathrm{O}_{3}$ conductances in terms of seasonal and interannual variation and to what extent environmental variables explain the variation. The analysis is limited to the growing season (weeks 15-45) only.

Weekly mean values of day-time ozone conductances throughout growing seasons are presented in Fig. 8a as the average over all years and for four selected years. Furthermore, a multi-variate analysis was performed to investigate which of the several parameters measured at the site are able to explain the variance in $\mathrm{O}_{3}$ conductance. Six environmental variables (air temperature $T_{\text {air }}$, vapor pressure deficit VPD, PAR, friction velocity $u_{*}$, soil temperature $T_{\text {soil }}$, and volumetric soil water content $\theta$ ), the photosynthetic capacity variable $\alpha$ and three ambient air concentrations relevant to $\mathrm{O}_{3}$ air chemistry $\left(\mathrm{NO}_{\mathrm{x}}\right.$, monoterpenes, and sesquiterpenes) were selected. First, the partial least squares (PLS) and stepwise regression techniques were applied in order to estimate statistical relationships between the environmental variables (plus $\alpha$ ) and the ozone conductance values over the nine years of data. Concurrent data of conductances and VOC concentrations were available for $4 \mathrm{yr}$ between 2007 and 2010, and 

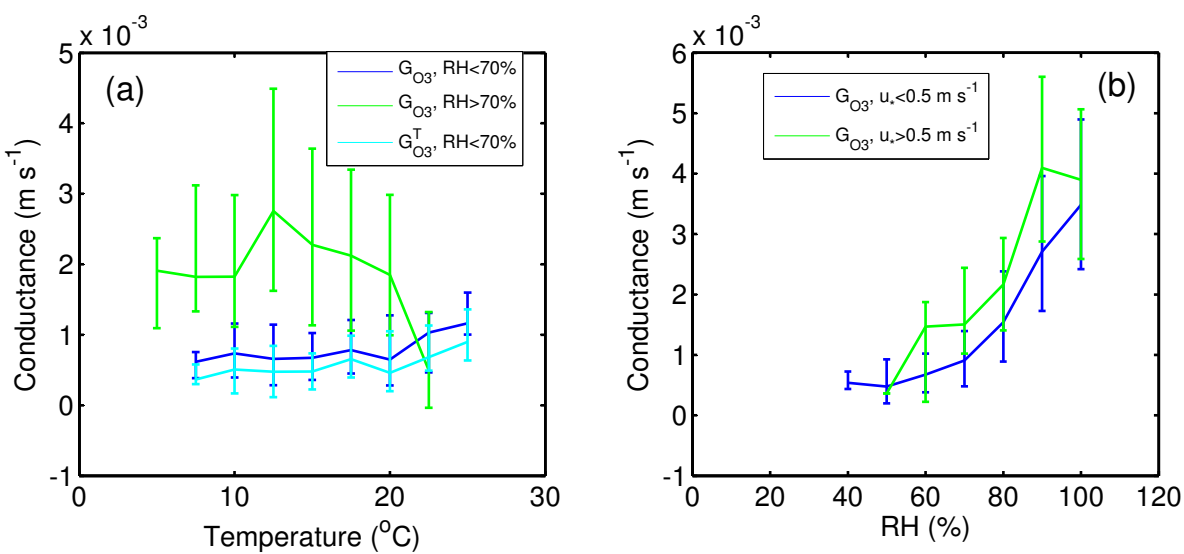

Fig. 7. Dependence of conductance on temperature (a) and RH (b) at night (elevation angle of Sun $<0^{\circ}$ ) during the peak of the growing season weeks 25-34. Medians of 30 min average observations together with quartiles are presented.

for this period the full vector of ten explaining variables was used in the multivariate analysis.

The multivariate analysis results are presented in Table 2. The analysis revealed that $\alpha$, VPD, PAR and monoterpene concentrations were identified as significant variables in explaining $G_{\mathrm{O}_{3}}$. Since the regression was performed on centred and scaled (with standard deviation) variables, the magnitude of coefficients describes the contribution of each variable to the variation of conductance. Therefore the photosynthetic capacity and water vapour pressure were the variables explaining the biggest fraction of variability. Furthermore, the PLC regression model was used to predict $G_{\mathrm{O}_{3}}$ on weekly average basis (the explained variance was $R^{2}=0.85$ ), Fig. $8 \mathrm{~b}$. For comparison, on daily average basis the explained variance was $R^{2}=0.79$. Comparison of the measurements and predictions enables to conclude that (i) the environmental variables that have been included in the present analysis were able to predict to large extent the observed variability during the course of the year, i.e., the seasonal variation with $98 \%$ of the variance being explained but (ii) failed to explain pattern in inter-annual differences (only $8 \%$ of the respective variance explained) such as elevated $G_{\mathrm{O}_{3}}$ during the weeks $33-35$ in 2005, systematically lower $G_{\mathrm{O}_{3}}$ during the weeks 35-39 in 2008 (Fig. 8a).

Figure 9 presents the non-stomatal conductance component similarly to Fig. 8. Estimation of the non-stomatal conductance is less accurate due to accumulation of errors when difference is calculated. The multivariate analysis results presented in Table 2 indicated that air temperature, VPD and monoterpene concentration were the significant environmental variables explaining the variation in $G_{\mathrm{O}_{3}}^{\mathrm{NS}}$ (however, the coefficient of determination was $R^{2}=0.46$ and $R^{2}=0.38$ on weekly and daily average data, respectively). On weekly basis the model explained $94 \%$ of the seasonal variation in $G_{\mathrm{O}_{3}}^{\mathrm{NS}}$ but failed to explain almost any inter-annual variability.
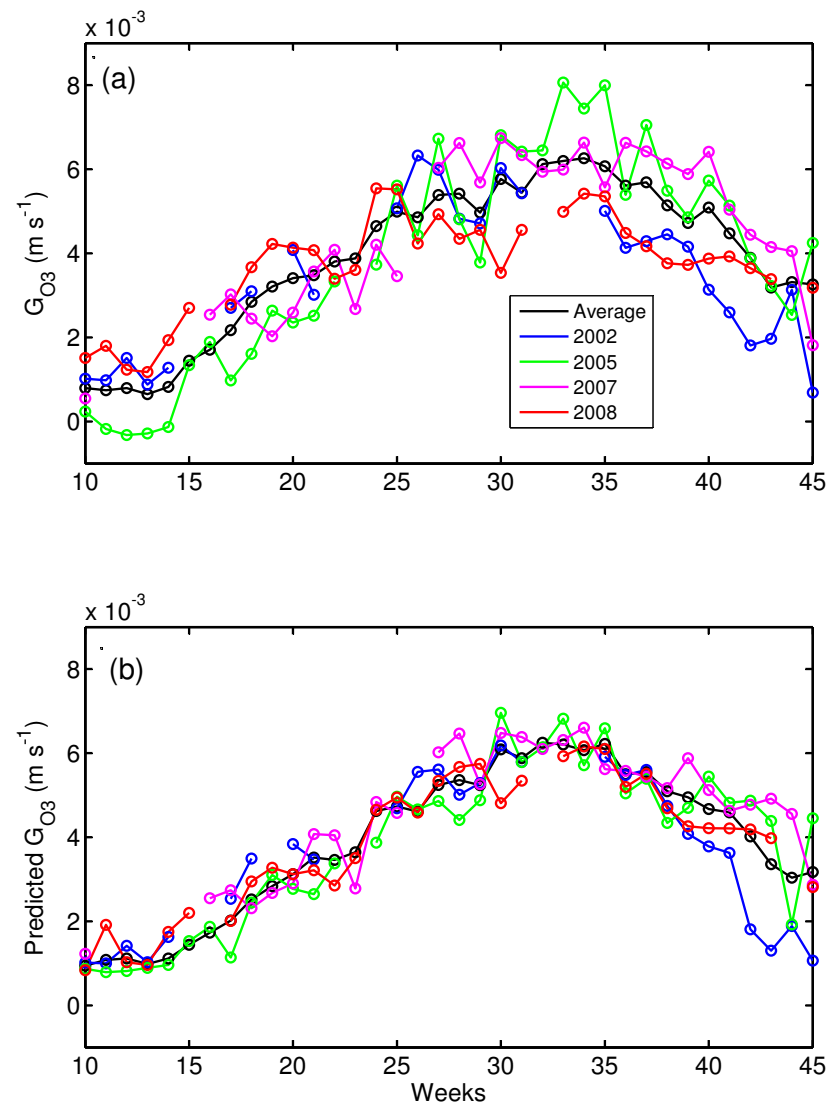

Fig. 8. Weekly average total $\mathrm{O}_{3}$ conductance for day-time conditions (elevation angle of sun $>10^{\circ}$ ) as observed (a) and predicted by using the partial least squares technique (b).

The soil surface temperature was the only variable with contradicting results from the multivariate analysis of $G_{\mathrm{O}_{3}}^{\mathrm{NS}}$ based on two different periods and explaining variable vectors. It was identified as significant variable being positively correlated with $G_{\mathrm{O}_{3}}^{\mathrm{NS}}$ in regression performed for the period 
Table 2. Multivariate regression coefficients and statistics relating daily average environmental variables and concentrations to the total $\mathrm{O}_{3}$ day-time conductance (upper table) and the non-stomatal $\mathrm{O}_{3}$ day-time conductance (lower table). PLC refers to the Partial Least Squares method of multivariate analysis. The models were applied to dimensionless data by performing centering and scaling with standard deviation of the time series. The photosynthetic capacity variable $\alpha$, air temperature $T_{\text {air }}$, vapor pressure deficit VPD, photosynthetically active radiation PAR, friction velocity $u_{*}$, soil temperature $T_{\text {soil }}$, volumetric soil water content $\theta$, and ambient air concentrations of $\mathrm{NO}_{\mathrm{x}}$, monoterpenes (MONOT) and sesquiterpenes (SESQUIT) were used as explaining variables. The status "In" denotes variables that we included in the final model by the Stepwise regression method. Bold lines denote significant explaining variables.

\begin{tabular}{|c|c|c|c|c|c|c|c|c|}
\hline \multirow[b]{3}{*}{ Variable } & \multicolumn{4}{|c|}{ 2001-2010 (excl. 2006) } & \multicolumn{4}{|c|}{ 2007-2010 } \\
\hline & PLC & \multicolumn{3}{|c|}{ Stepwise regression } & PLC & \multicolumn{3}{|c|}{ Stepwise regression } \\
\hline & coefficient & coefficient & Std error & Status & coefficient & coefficient & Std error & Status \\
\hline$\alpha$ & 0.57 & 0.60 & 0.04 & "In" & 0.99 & 0.74 & 0.12 & "In" \\
\hline$T_{\text {air }}$ & 0.30 & 0.31 & 0.04 & "In" & -0.21 & -0.23 & 0.38 & "Out" \\
\hline VPD & $-\mathbf{0 . 5 1}$ & -0.50 & 0.04 & "In" & -0.63 & -0.75 & 0.20 & "In" \\
\hline PAR & 0.12 & 0.12 & $\mathbf{0 . 0 3}$ & “In" & 0.48 & 0.35 & 0.19 & "In" \\
\hline$u_{*}$ & 0.00 & 0.00 & 0.02 & "Out" & 0.13 & 0.04 & 0.11 & "Out" \\
\hline$T_{\text {soil }}$ & 0.27 & 0.24 & 0.05 & "In" & -0.34 & -0.44 & 0.28 & "Out" \\
\hline$\theta$ & 0.01 & 0.01 & 0.02 & "Out" & -0.20 & -0.10 & 0.14 & "Out" \\
\hline $\mathrm{NO}_{\mathrm{x}}$ & & & & & 0.10 & 0.09 & 0.12 & "Out" \\
\hline MONOT & & & & & 0.38 & 0.25 & 0.11 & "In" \\
\hline SESQUIT & & & & & -0.12 & -0.13 & 0.11 & "Out" \\
\hline \multicolumn{9}{|c|}{ Non-stomatal $\mathrm{O}_{3}$ conductance } \\
\hline & \multicolumn{4}{|c|}{ 2001-2010 (excl. 2006) } & \multicolumn{4}{|c|}{ 2007-2010 } \\
\hline & PLC & \multicolumn{3}{|c|}{ Stepwise regression } & PLC & \multicolumn{3}{|c|}{ Stepwise regression } \\
\hline Variable & coefficient & coefficient & Std error & Status & coefficient & coefficient & Std error & Status \\
\hline$\alpha$ & -0.04 & -0.04 & 0.07 & "Out" & 0.45 & 0.34 & 0.29 & "Out" \\
\hline $\mathbf{T}_{\mathrm{air}}$ & 0.42 & 0.37 & 0.08 & “In” & $\mathbf{0 . 3 0}$ & 1.19 & 0.55 & "In" \\
\hline VPD & $-\mathbf{0 . 2 3}$ & $-\mathbf{0 . 2 0}$ & 0.07 & "In" & -0.34 & -0.82 & 0.36 & "In" \\
\hline PAR & -0.20 & -0.19 & 0.05 & "In" & 0.10 & -0.02 & 0.25 & "Out" \\
\hline$u_{*}$ & 0.00 & 0.00 & 0.03 & "Out" & 0.20 & 0.11 & 0.13 & "Out" \\
\hline$T_{\text {soil }}$ & 0.38 & 0.38 & 0.06 & "In" & -0.81 & -0.81 & 0.38 & "In" \\
\hline$\theta$ & -0.05 & -0.05 & 0.03 & "Out" & -0.51 & -0.56 & 0.19 & "In" \\
\hline $\mathrm{NO}_{\mathrm{x}}$ & & & & & -0.06 & -0.10 & 0.15 & "Out" \\
\hline MONOT & & & & & 0.59 & 0.42 & 0.14 & "In"' \\
\hline SESQUIT & & & & & -0.17 & -0.16 & 0.14 & "Out" \\
\hline
\end{tabular}

2001-2010, whereas the coefficient was negative for the period 2007-2010. It is obvious that environmental variables are cross-correlated and adding explaining variables can affect the regression output for other variables, this can explain the apparent contradiction in the statistical result of the soil temperature impact on $\mathrm{O}_{3}$ deposition.

\subsection{Air chemistry impact on ozone deposition}

Simulations to estimate the role of BVOC-s as non-stomatal sinks were performed by employing the numerical turbulent and stomatal exchange model described in Appendix A to C. As a case study, chemical degradation of ozone with $\beta$ caryophyllene was assumed originating from the temperature dependent canopy emission at temperature $20^{\circ} \mathrm{C}$. Figure 10 presents the simulation results for vertical profiles of concentrations of $\mathrm{O}_{3}$ and $\beta$-caryophyllene by using the emission potential $385 \mathrm{ng} \mathrm{g}^{-1}(\mathrm{dw}) \mathrm{h}^{-1}$. It is obvious that the concentration of $\mathrm{O}_{3}$ decreases towards the soil surface due to $\mathrm{O}_{3}$ canopy stomatal sink as well as chemical sink due to reaction with $\beta$-caryophyllene. Similarly, the $\mathrm{O}_{3}$ flux decreases towards surface. It is noteworthy that for $\mathrm{O}_{3}$ the vertical divergence of the turbulent flux, which occurs due to all possible $\mathrm{O}_{3}$ sources and sinks inside canopy, cannot be distinguished from stomatal sink term. This implies that chemical degradation plays minor role in $\mathrm{O}_{3}$ removal inside canopy in this case study. 

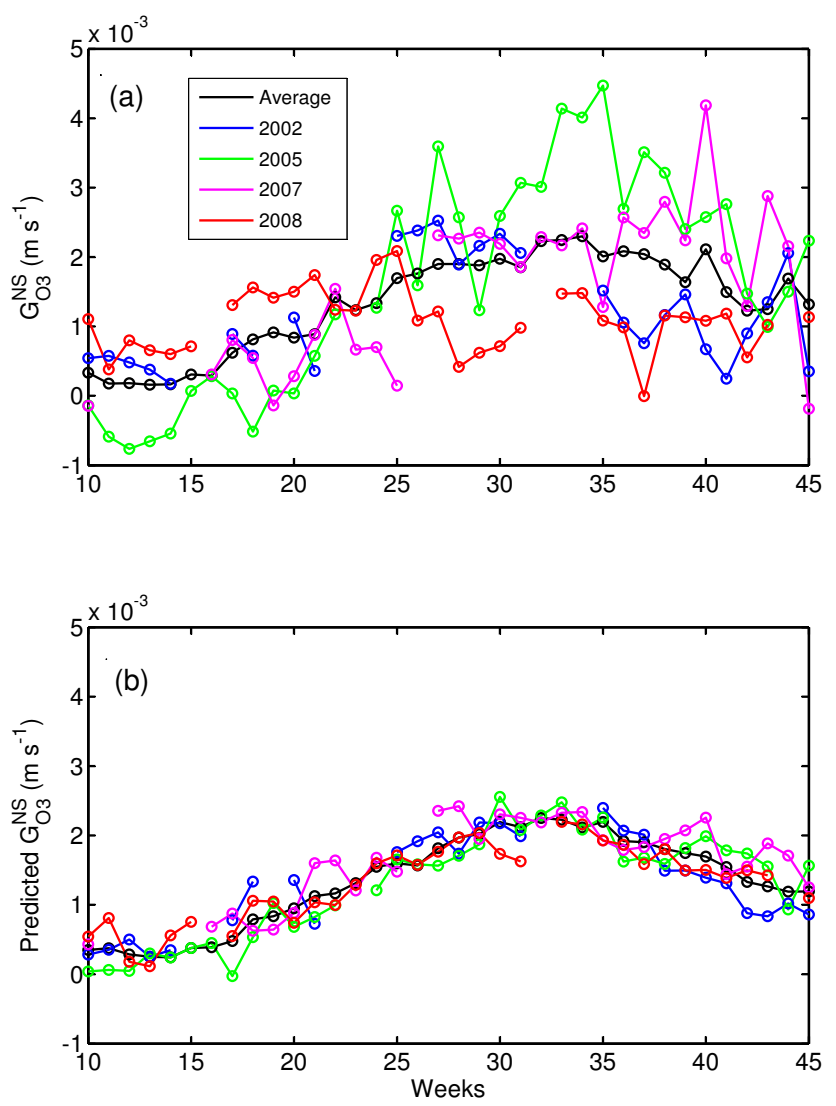

Fig. 9. Weekly average non-stomatal $\mathrm{O}_{3}$ conductance for day-time conditions (Solar elevation angle $>10^{\circ}$ ) as observed (a) and predicted by using the partial least squares technique (b).

$\beta$-caryophyllene instead is emitted by canopy foliage and therefore maximum concentration is located within canopy. The vertical turbulent flux of $\beta$-caryophyllene is upwards from the source maximum and also downwards (negative flux below $10 \mathrm{~m}$ ) due to the consumption of $\beta$-caryophyllene by reaction with ozone close to surface. It should be noted that the vertical flux divergence and canopy emission terms differ due to the additional chemical sink inside the canopy.

About $40 \%$ of emitted $\beta$-caryophyllene escaped from the canopy, whereas the non-stomatal ozone sink was estimated to be only from few tenths to few per cents depending on the assumption of emission strength. In case of the emission potential $10 \mu \mathrm{gg}^{-1}(\mathrm{dw}) \mathrm{h}^{-1}$ the chemical ozone sink inside the canopy comprised about $2 \%$. The simulation ignored diffusion path in laminar boundary layer around needles. Assuming that the fraction of $\beta$ caryophyllene reacting with ozone inside the canopy does not depend on emission strength, the emission potential for $\beta$-caryophyllene corresponding to $10 \%$ of ozone consumption is $45 \mu \mathrm{g} \mathrm{g}^{-1}(\mathrm{dw}) \mathrm{h}^{-1}$. Note that the emission potential defines the emission for temperature $30^{\circ} \mathrm{C}$ and at lower temperatures exponential decrease of emissions occur and the emission potential $45 \mu \mathrm{gg}^{-1}(\mathrm{dw}) \mathrm{h}^{-1}$ implies emission of approximately $7 \mu \mathrm{g} \mathrm{g}^{-1}(\mathrm{dw}) \mathrm{h}^{-1}$ at $20^{\circ} \mathrm{C}$. Alternatively, the following simple order of magnitude estimation can be done. Assuming that approximately $50 \%$ of BVOC-s reacts with ozone below the EC measurement level and ozone flux is $0.4 \mu \mathrm{g} \mathrm{m}^{-2} \mathrm{~s}^{-1}$, the emission rate of $0.34 \mu \mathrm{g} \mathrm{m}^{-2} \mathrm{~s}^{-1}$ $\left(1200 \mu \mathrm{g} \mathrm{m}^{-2} \mathrm{~h}^{-1}\right)$ would consume $10 \%$ of ozone below the EC level. This corresponds to VOC emission approximately $2.3 \mu \mathrm{g} \mathrm{g}^{-1}(\mathrm{dw}) \mathrm{h}^{-1}$. These emission estimates are far too high according to known emission studies (Hakola et al., 2006). Thus air chemistry of the given BVOC is not expected to contribute significantly to ozone deposition sink at our boreal forest site.

\section{Discussion and conclusions}

The results show that the $\mathrm{O}_{3}$ day-time total and stomatal conductance evolved throughout the growing season being the highest during the peak of the growing season. The non-stomatal fraction of conductance increased and achieved maximum in the end of the growing season (Table 1). The total day-time $\mathrm{O}_{3}$ deposition was higher at high $\mathrm{RH}$ compared to lower RH values, but the fraction of non-stomatal deposition was conserved. At night the total $\mathrm{O}_{3}$ conductance increased also along the growing season, being the highest during the peak growing season. Outside growing season the $\mathrm{O}_{3}$ conductance was much lower compared to growing season values.

The non-stomatal conductance comprised from 25 to $45 \%$ of the total conductance during day-time, the fraction being fairly independent of RH. Altimir et al. (2006) estimated for the same site from EC measurements based on 2002 and 2003 data that non-stomatal conductance contributed 25 to $42 \%$ of the total conductance under dry conditions and 59 to $65 \%$ under wet conditions (dry conditions were defined as $\mathrm{RH}<70 \%$, in addition excluding rainfalls and the posterior $12 \mathrm{~h}$ for the occurrence of $\mathrm{RH}>70 \%$ ). However, Altimir et al. (2006) used also night-time values in their analysis, which explains the higher fraction of non-stomatal deposition in their results under humid conditions.

The study addressed also the dependence of $\mathrm{O}_{3}$ conductances on environmental variables. Dependence of day-time total and non-stomatal conductance on RH was observed. The total $\mathrm{O}_{3}$ conductance depends obviously also on PAR through the stomatal component, but non-stomatal term revealed independence on PAR. At night high sensitivity of total $\mathrm{O}_{3}$ conductance on $\mathrm{RH}$ was observed.

Multivariate analysis was performed in order to relate seasonal and inter-annual variation in day-time conductances to environmental variables and concentrations of the nitrogen oxides, monoterpenes and sesquiterpenes. The analysis revealed that during the growing season $\alpha$, VPD, PAR and monoterpene concentrations were significant variables in explaining $G_{\mathrm{O}_{3}}$ (coefficient of determination $R^{2}=0.80$ ). For the non-stomatal conductance $G_{\mathrm{O}_{3}}^{\mathrm{NS}}$ air temperature, VPD 

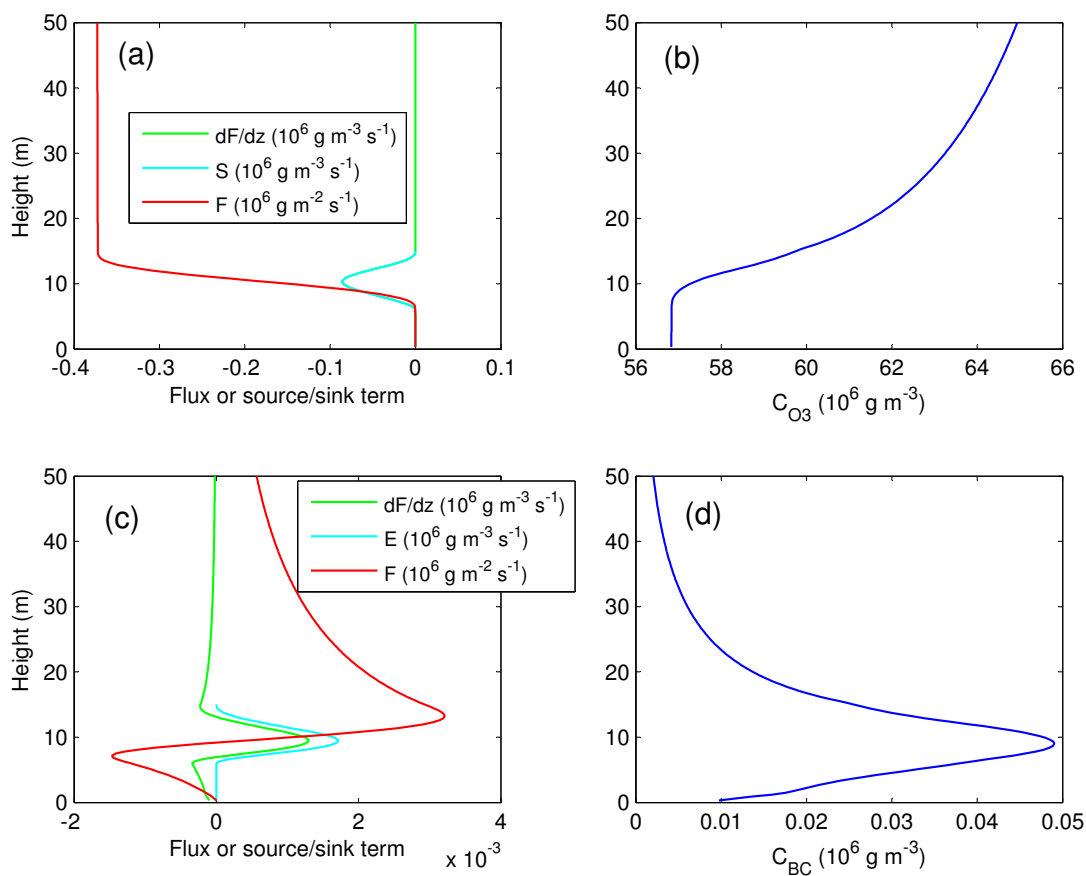

Fig. 10. Vertical profiles of modelled ozone $\left(C_{\mathrm{O}_{3}}\right.$, panel b) and $\beta$-caryophyllene $\left(C_{\beta-C}\right.$, panel d) concentrations and vertical turbulent fluxes $(F)$, turbulent flux gradients $\left(\mathrm{d} F / \mathrm{d} z\right.$ ) and source (for $\beta$-caryophyllene the emission denoted by $S_{\mathrm{e}}$ ) or sink (for $\mathrm{O}_{3}$ stomatal sink denoted by $S$ ) terms for (a) $\mathrm{O}_{3}$ and (c) $\beta$-caryophyllene. Temperature $20^{\circ} \mathrm{C}$ and emission potential $385 \mathrm{ng} \mathrm{g}^{-1}(\mathrm{dw}) \mathrm{h}^{-1}$ was assumed; $C_{\mathrm{O}_{3}}(h)=$ $30 \mathrm{ppb}$ as the boundary condition for ozone concentration was applied; radiation above canopy was taken as $I_{\mathrm{b}, \mathrm{h}}=800 \mu \mathrm{mol} \mathrm{m}^{-2} \mathrm{~s}^{-1}$ and $I_{\mathrm{d}, \mathrm{h}}=200 \mu \mathrm{mol} \mathrm{m}{ }^{-2} \mathrm{~s}^{-1}$; following optimal stomatal model parameters were used: $\alpha=0.0012 \mathrm{~m} \mathrm{~s}^{-1}, \gamma=2200 \mu \mathrm{molm} \mathrm{m}^{-2} \mathrm{~s}^{-1}, \lambda=$ $4 \times 10^{-3} \mathrm{~g} \mathrm{CO}_{2}\left(\mathrm{~g} \mathrm{H}_{2} \mathrm{O}\right)^{-1}$. Atmospheric boundary layer height was set to $300 \mathrm{~m}$.

and monoterpene concentration were the significant environmental variables (the coefficient of determination was only $R^{2}=0.38$ ). It can be concluded that multivariate regression model was able to predict similar variation with the observations during the course of the growing season but failed to explain the major inter-annual differences. It would be expected that the inter-annual differences would be controlled by parameter(s) that respond on relatively long timescales. The parameters that operate at these timescales are e.g., soil moisture status and phenology (described by the photosynthetic capacity parameter $\alpha$ of the optimal stomatal model). Soil temperature is also a slowly varying parameter, but does not perform as a significant parameter in terms of explaining power of ozone deposition. Currently we do not know why the inter-annual variability in ozone deposition was poorly explained. It could be due to episodic events that are not described by the set of explaining variables used in our study.

Multiple studies have addressed the role of nitrogen oxides as potential chemical sink of ozone (Walton et al., 1997; Gao et al., 1993). However, while acknowledging the role of nitrogen chemistry in affecting ozone concentrations inside the ABL, the effect to ozone fluxes during the transport path from above canopy to sinks located within canopy was found to be negligible. Gao et al. (1993) included also isoprene and its oxidation products in chemical reaction chain. The au- thors concluded that $\mathrm{O}_{3}$ and isoprene profiles and fluxes were close to non-reactive scenario, but the profiles and fluxes of $\mathrm{NO}, \mathrm{NO}_{2}$ and $\mathrm{NO}_{\mathrm{x}}$ were strongly affected by chemistry. The $\mathrm{NO}_{\mathrm{x}}$ emission fluxes at the site are very low. According to measurements at site both $\mathrm{N}_{2} \mathrm{O}$ and $\mathrm{NO}$ are emitted from the soil and $\mathrm{NO}_{2}$ was deposited into the soil. During the campaign in the autumn 2011 measured NO-N emission was around $0.01 \mathrm{~kg} \mathrm{Nha}^{-1} \mathrm{yr}^{-1}$ and $\mathrm{NO}_{2}-\mathrm{N}$ deposition was even smaller, which was challenging to quantify because of the small fluxes (Korhonen et al., 2012). The multivariate analysis performed in current study did not identify $\mathrm{NO}_{\mathrm{x}}$ concentration as significant variable explaining $\mathrm{O}_{3}$ conductance in day-time.

Stroud et al. (2005) simulated the canopy photochemistry including $\alpha, \beta$-pinene and $\beta$-caryopyllene as the surrogate for reactive sesquiterpenes. They reported a $30 \%$ escape efficiency for $\beta$-caryophyllene and $90 \%$ escape efficiency for $\alpha, \beta$-pinene in a Loblolly pine forest for midday summertime conditions. Our simulation with simple chemistry including only $\mathrm{O}_{3}$ chemistry with $\beta$-caryopyllene predicted an escape efficiency of about $40 \%$, being close to the results of Rinne et al. (2012) and Stroud et al. (2005). Rinne et al. (2012) have used the Lagrangian Stochastic dispersion model, free of the limitations of the K-theory based approach used in our study. By performing more detailed chemical reaction simulations, 
Stroud et al. (2005) reported that $\beta$-caryopyllene loss was dominated by $\mathrm{O}_{3}$-kinetics, thus our $\beta$-caryopyllene escape efficiency should be a reasonable estimate. Similarly to our conclusion, Stroud et al. (2005) found that $\mathrm{O}_{3}$ gas phase chemistry was not contributing significantly to canopy-scale $\mathrm{O}_{3}$ loss, admitting that the result depended critically on assumed sesquiterpene emission rate.

The emission potential of $\beta$-caryophyllene (the dominating sesquiterpene in Scots pine emissions at SMEAR II) is varying at the site and is reported to range from 160 to $380 \mathrm{ng} \mathrm{g}^{-1}(\mathrm{dw}) \mathrm{h}^{-1}$. The emission potentials for dominant monoterpene, 3-carene, have been reported to be $4000 \mathrm{ng} \mathrm{g}^{-1}(\mathrm{dw}) \mathrm{h}^{-1}$ in early summer at its maximum, total monoterpenes being represented by $5200 \mathrm{ng} \mathrm{g}^{-1}(\mathrm{dw}) \mathrm{h}^{-1}$ (Tarvainen et al., 2005; Hakola et al., 2006). Thus, emission potential of monoterpenes is approximately an order of magnitude larger than that of sesquiterpenes. However, the reaction rates of $\beta$-caryophyllene and 3-carene with ozone are $1.2 \times 10^{-14}$ and $4 \times 10^{-17} \mathrm{~cm}^{3} \mathrm{molec}^{-1} \mathrm{~s}^{-1}$, respectively, differing by more than two orders of magnitude. Based on this knowledge monoterpenes, as represented by dominant compound 3-carene, cannot be a significant non-stomatal sink inside canopy air space. This observation was also supported by Rinne et al. (2012), who found that more than $90 \%$ of monoterpene $\alpha$-pinene escaped canopy at night, with respective figure being close to $100 \%$ during day-time. Thus our current knowledge of monoterpene emissions does not support their significant role in ozone degradation inside canopy air space. Recent findings have also emphasised the possible role of circadian control of the emissions of naturally produced hydrocarbons (Archibald, 2011). Nevertheless, the earlier studies at SMEAR II have confirmed the temperature dependence of those emissions (Hakola et al., 2006) and there is no experimental evidence of circadian control mechanism available.

The multivariate analysis did not reveal dependence of $\mathrm{O}_{3}$ total and non-stomatal conductances on turbulence intensity. Turbulent transport time is directly related to turbulence intensity and the ratio of this time-scale to chemical reactionrate time-scale should affect the non-stomatal deposition. The result therefore does not support the role of chemical sinks in canopy air space as $\mathrm{O}_{3}$ removal mechanism. Alternatively, the impact of the time scales could be statistically counted directly by relevant monoterpene or sesquiterpene concentrations.

The multivariate analysis performed to explain total and non-stomatal $\mathrm{O}_{3}$ conductance indicated independence on measured sesquiterpene concentration but revealed significant correlation with monoterpene concentration. Our simulation of the impact of $\beta$-caryopyllene as the surrogate for sesquiterpenes on the chemical sink of $\mathrm{O}_{3}$ inside canopy suggested that the compound is not likely the BVOC performing as significant $\mathrm{O}_{3}$ sink inside canopy, in line with the result of multivariate analysis. The compound was chosen because of its relatively fast reaction rate with $\mathrm{O}_{3}$. Monoterpenes are known to have relatively slow reactivity with $\mathrm{O}_{3}$ compared to turbulent transport time inside canopy. Nevertheless, our statistical result suggested a correlation between monoterpenes and $\mathrm{O}_{3}$ non-stomatal sink inside canopy. However, this is indirect evidence and might imply role of some other compound which concentration correlates with monoterpenes. Another possibility is that a major part of the ozonolysis is happening not in the canopy air but in another place, for example, much closer to the surfaces within the surface boundary layer of the needles.

The results clearly show the importance of several nonstomatal removal mechanisms. Recent in situ chemistry measurements indicate that the coniferous canopy air space possesses a large, unknown sink for OH (Nölscher et al., 2012). The study suggested that complex yet unknown reactions between the biogenic terpenes or some secondary reaction products may explain the missing $\mathrm{OH}$ sink. Detailed models for $\mathrm{O}_{3}$ deposition are similarly suffering from the lack of detailed knowledge of participating compounds and we do not expect that more complicated model calculations involving a wide range of reactive compounds would yield a better understanding of $\mathrm{O}_{3}$ chemical non-stomatal sinks in canopy air space. Therefore more reliable quantification of compounds participating in $\mathrm{O}_{3}$ chemistry cannot be done in the present analysis by modelling approach.

In summary, it was determined that day-time non-stomatal ozone deposition was mainly explained by vapour pressure deficit (VPD), temperature, and monoterpene concentration. However, known emissions of monoterpenes are not able to affect significantly ozone deposition in canopy air space. This is consistent with the result that friction velocity, affecting the turbulent transport time, did not exhibit a clear impact on $\mathrm{O}_{3}$ non-stomatal deposition. Such dependence would be expected if turbulent transport time would be in the same order as the chemical reaction time scale. Therefore, it is likely that other unknown chemical compounds or processes correlating with the ozone deposition rates, including potentially reactions at the surfaces, are responsible for non-stomatal sink term. However, their relative contributions were not possible to quantify from canopy-level measurements. Also the fact that the used set of variables did not explain the interannual variability of $\mathrm{O}_{3}$ depositions suggests that some still unknown mechanisms might be involved in $\mathrm{O}_{3}$ deposition process.

\section{Appendix A}

\section{Coupled turbulent and stomatal exchange multi-layer model for forest canopy}

The conservation equation for average mixing ratio of a scalar $\bar{C}$ inside canopy, assuming stationary and horizontally homogeneous conditions along with the first-order closure 
applied to vertical turbulent flux, can be written as

$$
\frac{\partial}{\partial z}\left(-D_{\mathrm{t}}(z) \frac{\partial \bar{C}}{\partial z}\right)+a(z) g\left(\bar{C}-\bar{C}_{\mathrm{i}}\right)-S_{\mathrm{a}}=0,
$$

where $g$ denotes conductance, $D_{\mathrm{t}}$ turbulent diffusivity, $a$ all-sided leaf area and $\bar{C}_{\mathrm{i}}$ the intercellular value of $\bar{C}$ (for $\mathrm{O}_{3}$ the inter-cellular concentration was taken zero). $S_{\mathrm{a}}$ is the source/sink term in canopy air space, being positive for source and negative for sink, and is applicable only for ozone and other quantities experiencing chemical degradation in canopy air space.

In optimal theory of stomatal control the stomatal conductance $g_{\mathrm{s}}$ for carbon dioxide can be presented as

$$
g_{\mathrm{s}}=\alpha\left(\sqrt{\frac{\bar{C}}{\lambda \frac{D_{\mathrm{H}_{2} \mathrm{O}}}{D_{\mathrm{CO}_{2}}}\left(\left[\mathrm{H}_{2} \mathrm{O}\right]_{\mathrm{i}}-\left[\mathrm{H}_{2} \mathrm{O}\right]\right)}}-1\right) f(I),
$$

where $\alpha$ is the parameter of photosynthetic capacity, $\lambda$ is the cost of transpiration, $\left[\mathrm{H}_{2} \mathrm{O}\right]$ the water vapour concentration in the air, "i" denoting the intercellular value, and $f(I)$ the function describing saturation of photosynthesis with radiation by making use of light saturation parameter $\gamma$ :

$f(I)=\frac{I}{I+\gamma}$.

Due to radiative heating and cooling the effective temperature of canopy foliage does not equal that of air temperature. To account for this effect in calculation of the intercellular water content $\left[\mathrm{H}_{2} \mathrm{O}\right]_{\mathrm{i}}$ (assumed to be the saturated water content at needle temperature), the effective canopy foliage temperature was calculated from

$T_{\text {eff }}=T_{\mathrm{r}}+\frac{H}{\rho c_{p}}\left(R_{\mathrm{b}}+R_{\mathrm{a}}\right)$,

where $T_{\mathrm{r}}$ is the temperature at reference height, $H$ is the sensible heat flux measured by the eddy covariance, $\rho$ the air density, $c_{p}$ the heat capacity of air at constant pressure and $R_{\mathrm{a}}$ the aerodynamic resistance as defined by Eq. (A12). The bulk canopy laminar boundary layer resistance $R_{\mathrm{b}}$ was inferred from multi-layer modelling by replacing the conductance $g$ with laminar boundary layer conductance

$g_{\mathrm{b}}=\left[\sqrt{-\overline{u^{\prime} w^{\prime}}(z)}\left(\frac{c_{\mathrm{v}}}{c_{\mathrm{d}}} S c^{-2 / 3}\right)\right]$,

where $\overline{u^{\prime} w^{\prime}}(z)$ is the momentum flux at level $z, \frac{c_{\mathrm{v}}}{c_{\mathrm{d}}}(=1 / 3)$ is the ratio of viscous to total drag (Slinn, 1982) and $S c$ the Schmidt number.

For carbon dioxide assimilation the net exchange rate becomes

$g\left(\bar{C}-\bar{C}_{\mathrm{i}}\right)=\frac{\alpha f(I)\left(g_{\mathrm{s}} \bar{C}+r_{\mathrm{f}}\right)}{g_{\mathrm{s}}+\alpha f(I)}-r_{\mathrm{f}}$, where $r_{\mathrm{f}}$ presents foliage respiration. The foliage respiration was presented as

$r_{\mathrm{f}}=r_{0} 2.3^{T / 10}$

with $r_{0}$ being the respiration parameter and $T$ the needle temperature in ${ }^{\circ} \mathrm{C}$.

Turbulent diffusivity was parameterised according to $D_{\mathrm{t}}=$ $\tau \sigma_{w}^{2}$, where $\tau$ and $\sigma_{w}$ represent the Lagrangian turbulent time scale and the standard deviation of vertical velocity, respectively. Turbulent flux at height $z$ is expressed as

$F(z)=-D_{\mathrm{t}} \frac{\partial \bar{C}}{\partial z}$.

The boundary condition $\bar{C}\left(z_{\mathrm{r}}\right)=\bar{C}_{\mathrm{r}}$ was applied together with the soil respiration flux assumption at soil surface (ground vegetation was presented as a layer close to surface) for carbon dioxide. The lower boundary condition for water vapour was obtained following consideration presented by Parlange and Katul (1992), assuming proportionality of soil evaporation to net radiation at soil surface, that was assumed to be fraction of global radiation at soil surface. The proportionality was scaled such that the modelled soil evaporation together with transpiration from ground vegetation corresponded to observations at site (Launiainen et al., 2005). The soil evaporation was limited by the soil water content and temperature according to

$\mathrm{LE}_{\mathrm{S}}=R_{\mathrm{N}} 1.26 \vartheta \frac{\Delta}{\Delta+\Gamma}$,

where $R_{\mathrm{N}}$ is the net radiation, $\Delta=\frac{\partial S}{\partial T}$ is the temperature derivative of the saturated vapour pressure and $\Gamma$ is the psycrometric constant. $\vartheta$ was parameterised according to Bartlett et al. (2003)

$\vartheta=0.25\left(1-\cos \left(\pi \frac{\theta}{\theta_{\mathrm{S}}}\right)\right)^{2}$,

where $\theta$ is the volumetric soil water content and $\theta_{\mathrm{S}}$ is the value at field capacity.

For ozone the soil surface flux was assumed to be zero and therefore the modelled ozone deposition represented fully stomatal deposition.

For estimation of the deposition velocity at canopy top a numerical integration over canopy layers was performed with vertical profiles of $\tau$ and $\sigma_{w}^{2}$ parameterised according to Launianen et al. (2007).

Deposition velocity at the measurement height $z_{\mathrm{r}}$ is given by

$V\left(z_{\mathrm{r}}\right)=\frac{1}{R_{\mathrm{a}}+\frac{1}{V(h)}}$

with the aerodynamic resistance $R_{\mathrm{a}}$ estimated as

$R_{\mathrm{a}}=\frac{\bar{U}\left(z_{\mathrm{r}}\right)-\bar{U}(h)}{u_{*}^{2}}$. 


\section{Appendix B}

\section{Radiation attenuation model inside canopy}

The direct beam $I_{\mathrm{b}, \mathrm{h}}$ and diffuse $I_{\mathrm{d}, \mathrm{h}}$ radiation values above canopy were obtained from measurements. Inside the canopy simple attenuation model was assumed. The fraction of sunlit areas inside canopy was defined by $\tau_{\mathrm{b}}$ and that of shade by $\left(1-\tau_{\mathrm{b}}\right)$ respectively, with

$\tau_{\mathrm{b}}=\exp \left(-K_{\mathrm{b}} L_{\mathrm{c}} P / \sin \left(h_{\oplus}\right)\right)$

denoting the attenuation coefficient for direct beam radiation (extinction coefficient $K_{\mathrm{b}}=0.7$, clumping factor $P=0.83$, $L_{\mathrm{c}}$ being the cumulative projected leaf area above level and $h_{\oplus}$ the solar elevation angle). The solar irradiance at sunlit area $I_{\mathrm{sl}}$ was calculated from the direct beam $I_{\mathrm{b}, \mathrm{h}}$ at the canopy top and diffuse component at the canopy top $I_{\mathrm{d}, \mathrm{h}}$ as

$I_{\mathrm{sl}}=I_{\mathrm{b}, \mathrm{h}}+\tau_{\mathrm{d}} I_{\mathrm{d}, \mathrm{h}}$,

where

$\tau_{\mathrm{d}}=\exp \left(-K_{\mathrm{d}} L_{\mathrm{c}} P\right)$,

with extinction coefficient $K_{\mathrm{d}}=0.7$. The irradiance at shaded area $I_{\mathrm{sh}}$ was calculated as $I_{\mathrm{sh}}=\tau_{\mathrm{d}} I_{\mathrm{d}, \mathrm{h}}$.

\section{Appendix C}

\section{Emission rates of organic compounds}

Temperature dependent emission was directly modelled by term $S_{\mathrm{e}}$ (assumed that $S_{\mathrm{e}}$ presents effectively the emission rate at leaf laminar boundary layer top) according to Guenther et al. (1993)

$S_{\mathrm{e}}=\frac{\mathrm{LAD}(z)}{\mathrm{LAI}} \varepsilon c(T)$,

with

$c(T)=\exp \left(\beta\left(T_{\mathrm{K}}-T_{\mathrm{s}}\right)\right)$,

with $T_{\mathrm{S}}=303.13 \mathrm{~K}$ as the leaf temperature at standard conditions and $T_{\mathrm{K}}$ representing the actual temperature in $\mathrm{K}$. According to Hakola et al. (2006) the coefficient $\beta$ describing the strength of the temperature dependence is $0.19 \mathrm{~K}^{-1}$ for the pine forest at SMEAR II.

The sink term of both compounds, ozone and selected organic compound $\beta$-caryophyllene, in molec $\mathrm{cm}^{-3} \mathrm{~s}^{-1}$ was calculated as

$S_{\mathrm{a}}=-k\left[\mathrm{O}_{3}\right][\beta$-caryophyllene $]$.

The reaction rate was taken to be $k=1.2 \times 10^{-14} \mathrm{~cm}^{3}$ $\mathrm{molec}^{-1} \mathrm{~s}^{-1}$.
Acknowledgements. This work was supported by the Academy of Finland Centre of Excellence Program and European Commission projects. Nuria Altimir acknowledges the funding received from the European Union Seventh Framework Programme (FP7/2007-2013) under grant agreement no. 275855. We gratefully acknowledge support from the project "Effects of Climate Change on Air Pollution Impacts and Response Strategies for European Ecosystems" (ÉCLAIRE), funded under the EC 7th Framework Programme (Grant Agreement No. 282910).

Edited by: P. Artaxo

\section{References}

Altimir, N., Tuovinen, J.-P., Vesala, T., Kulmala, M., and Hari, P.: Measurements of ozone removal to Scots pine shoots: calibration of a stomatal uptake model including the non-stomatal component, Atmos. Environ., 38, 2387-2398, 2004.

Altimir, N., Kolari, P., Tuovinen, J.-P., Vesala, T., Bäck, J., Suni, T., Kulmala, M., and Hari, P.: Foliage surface ozone deposition: a role for surface moisture?, Biogeosciences, 3, 209-228, doi:10.5194/bg-3-209-2006, 2006.

Archibald, A.: Wake-up call for isoprene emissions, Nat. Geosci., 4, 659-660, 2011.

Barlett, P.A., McCaughey, J. H., Laufleur, P. M., and Verseghy, D. L.: Modelling evapotranspiration at three boreal forest stands using the CLASS: tests of parameterizations for canopy conductance and soil evaporation, Int. J. Climatol., 23, 427-451, doi:10.1002/joc.884, 2003.

Coyle, M.: The Gaseous Exchange of Ozone at Terrestrial Surfaces: Non-stomatal Deposition to Grassland, Ph.D. thesis, University of Edinburgh, UK, 2005.

Coyle, M., Nemitz, E., Storeton-West, R., Fowler, D., and Cape, J. N.: Measurements of ozone deposition to a potato canopy, Agr. Forest Meteorol., 149 , 655-666, 2009.

Erisman, J. W., Vermeulen, A., Hensen, A., Flechard, C. R., Dämmgen, U., Fowler, D., Sutton, M. A., Grünhage, L., and Tuovinen, J.-P.: Monitoring and modelling of biosphere/atmosphere exchange of gases and aerosols in Europe, Environ. Pollut., 133, 403-413, 2005.

Fares, S., McKay, M., Holzinger, R., and Goldstein, A. H.: Ozone fluxes in a Pinus ponderosa ecosystem are dominated by nonstomatal processes: Evidence from long-term continuous measurements, Agr. Forest Meteorol., 150, 420-431, 2010.

Fowler, D., Flechard, C. R., Cape, J. N., Storeton-West, R. L., and Coyle, M.: Measurements of ozone deposition to vegetation quantifying the flux, the stomatal and non-stomatal components, Water Air Soil Pollut., 130, 63-74, 2001.

Fowler, D., Pilegaard, K., Sutton, M. A., Ambus, P., Raivonen, M., Duyzer, J., Simpson, D., Fagerli, H., Schjoerring, J. K., Neftel, A., Burkhardt, J., Daemmgen, U., Neirynck, J., Personne, E., Wichink-Kruit, R., Butterbach-Bahl, K., Flechard, C., Tuovinen, J. P., Coyle, M., Fuzzi, S., Gerosa, G., Granier, C., Loubet, B., Altimir, N., Gruenhage, L., Ammann, C., Cieslik, S., Paoletti, E., Mikkelsen, T. N., Ro-Poulsen, H., Cellier, P., Cape, J. N., Isaksen, I. S. A., Horváth, L., Loreto, F., Niinemets, Ü., Palmer, P. I., Rinne, J., Laj, P., Maione, M., Misztal, P., Monks, P., Nemitz, E., Nilsson, D., Pryor, S., Gallagher, M. W., Vesala, T., Skiba, U., Brüggemann, N., Zechmeister-Boltenstern, S., Williams, J., 
O’Dowd, C., Facchini, M. C., de Leeuw, G., Flossman, A., Chaumerliac, N., and Erisman, J. W.: Atmospheric composition change: ecosystems - Atmosphere interactions, Atmos. Environ., 43, 5193-5267, 2009.

Gao, W, Wesely, M. L., and Doskey, P. V.: Numerical Modeling of the Turbulent Diffusion and Chemistry of $\mathrm{NO}_{\mathrm{x}}, \mathrm{O}_{3}$, Isoprene, and Other Reactive Trace Gases in and Above a Forest Canopy, J. Geophys. Res., 98, 18339-18353, doi:10.1029/93JD01862, 1993.

Goldstein, A. H., McKay, M., Kurpius, M. R., Schade, G. W., Lee, A., Holzinger, R., and Rasmussen, R. A.: Forest thinning confirms ozone deposition to forest canopy is dominated by reaction with biogenic VOCs, Geophys. Res. Let., 31, L22106, doi:10.1029/2004GL021259, 2004.

Goulden, M., Munger, J. W., Fan, S.-M., Daube, B. C., and Wofsy, S. C.: Measurements of carbon sequestration by long-term eddy covariance: methods and a critical evaluation of accuracy, Glob. Change Biol., 2, 169-182, 1996.

Guenther, A.: Seasonal and spatial variations in natural volatile organic compound emissions, Ecol. Appl., 7, 34-45, 1997.

Guenther, A., Zimmerman, P. R., Harley, P. C., Monson, R. K., and Fall, R.: Isoprene and monoterpene emission rate variability: Model evaluations and sensitivity analyses, J. Geophys. Res., 98, 12609-12617, 1993.

Hakola, H., Tarvainen, V., Bäck, J., Ranta, H., Bonn, B., Rinne, J., and Kulmala, M.: Seasonal variation of mono- and sesquiterpene emission rates of Scots pine, Biogeosciences, 3, 93-101, doi:10.5194/bg-3-93-2006, 2006.

Hari, P. and Kulmala, M.: Station for measuring ecosystematmosphere relations (SMEAR II), Boreal Environ. Res., 10, 315-322, 2005.

Holzinger, R., Lee, A., Paw, K. T., and Goldstein, U. A. H.: Observations of oxidation products above a forest imply biogenic emissions of very reactive compounds, Atmos. Chem. Phys., 5, 67-75, doi:10.5194/acp-5-67-2005, 2005.

Holzinger, R., Lee, A., McKay, M., and Goldstein, A. H.: Seasonal variability of monoterpene emission factors for a ponderosa pine plantation in California, Atmos. Chem. Phys., 6, 1267-1274, doi:10.5194/acp-6-1267-2006, 2006.

Ilvesniemi, H. and Liu, C.: Biomass distribution in a young Scots pine stand, Boreal Environ. Res., 6, 3-8, 2001.

Korhonen, J. F. J., Pihlatie, M., Pumpanen, J., Aaltonen, H., Hari, P., Levula, J., Kieloaho, A.-J., Nikinmaa, E., Vesala, T., and Ilvesniemi, H.: Nitrogen balance of a boreal Scots pine forest, Biogeosciences Discuss., 9, 11201-11237, doi:10.5194/bgd-911201-2012, 2012.

Keronen, P., Reissell, A., Rannik, Ü., Pohja, T., Siivola, E., Hiltunen, V., Hari, P., Kulmala, M., and Vesala, T.: Ozone flux measurements over a Scots pine forest using eddy covariance method: performance evaluation and comparison with fluxprofile method, Boreal Environ. Res., 8, 425-443, 2003.

Kurpius, M. R. and Goldstein, A. H.: Gas-phase chemistry dominates $\mathrm{O}_{3}$ loss to a forest, implying a source of aerosols and hydroxyl radicals to the atmosphere, Geophys. Res. Lett., 30, 1371, doi:10.1029/2002GL016785, 2003.

Lamaud, E., Carrara, A., Brunet, Y., Lopez, A., and Druilhet, A.: Ozone fluxes above and within a pine forest canopy in dry and wet conditions, Atmos. Environ., 36, 77-88, 2002.
Lamaud, E., Loubet, B., Irvine, M., Stella, P., Personne, E., and Cellier, P.: Partitioning of ozone deposition over a developed maize crop between stomatal and non-stomatal uptakes, using eddycovariance flux measurements and modelling, Agr. Forest Meteorol., 149, 1385-1396, 2009.

Launiainen, S., Rinne, J., Pumpanen, J., Kulmala, L., Kolari, P., Keronen, P., Siivola, E., Pohja, T., Hari, P., and Vesala, T.: Eddy covariance measurements of $\mathrm{CO}_{2}$ and sensible and latent heat fluxes during full year in a boreal pine forest trunk-space, Boreal Environ. Res., 10, 569-588, 2005.

Launiainen, S., Vesala, T., Mölder, M., Mammarella, I., Smolander, S., Rannik, Ü., Kolari, P., Hari, P., Lindroth, A., and Katul, G.: Vertical variability and effect of stability on turbulence characteristics down to the floor of a pine forest, Tellus, 59B, 919-936, 2007.

Lindroth, A., Grelle, A., and Moren, A.-S.: Long-term measurments of boreal forest carbon balance reveal large temperature sensitivity, Glob. Change Biol., 4, 443-450, 1998.

Mammarella, I., Launiainen, S., Gronholm, T., Keronen, P., Pumpanen, J., Rannik, Ü., and Vesala, T.: Relative humidity effect on the high frequency attenuation of water vapour flux measured by a closed-path eddy covariance system, J. Atmos. Ocean. Tech., 26, 1856-1866, 2009.

Massman, W. J.: Toward an ozone standard to protect vegetation based on effective dose: a review of deposition resistances and a possible metric, Atmos. Environ., 38, 2323-2337, 2004.

McMillen, R.: An eddy correlation technique with extended applicability to non-simple terrain, Bound.-Lay. Meteorol., 43, 231245, 1998.

Mészáros, R., Horváth, L., Weidinger, T., Neftel, A., Nemitz, E., Dämmgen, U., Cellier, P., and Loubet, B.: Measurement and modelling ozone fluxes over a cut and fertilized grassland, Biogeosciences, 6, 1987-1999, doi:10.5194/bg-6-1987-2009, 2009.

Nölscher, A. C., Williams, J., Sinha, V., Custer, T., Song, W., Johnson, A. M., Axinte, R., Bozem, H., Fischer, H., Pouvesle, N., Phillips, G., Crowley, J. N., Rantala, P., Rinne, J., Kulmala, M., Gonzales, D., Valverde-Canossa, J., Vogel, A., Hoffmann, T., Ouwersloot, H. G., Vilà-Guerau de Arellano, J., and Lelieveld, J.: Summertime total $\mathrm{OH}$ reactivity measurements from boreal forest during HUMPPA-COPEC 2010, Atmos. Chem. Phys., 12, 8257-8270, doi:10.5194/acp-12-8257-2012, 2012.

Parlange, M. B. and Katul, G. G.: Estimation of the diurnal variation of potential evaporation from a wet bare soil surface, J. Hydrol., 132, 71-89, 1992.

Rannik, Ü., Keronen, P., Hari, P., and Vesala, T.: Estimation of forest-atmosphere $\mathrm{CO}_{2}$ exchange by direct and profile techniques, Agr. Forest. Meteorol., 126, 141-155, 2004.

Rannik, Ü., Mammarella, I., Keronen, P., and Vesala, T.: Vertical advection and nocturnal deposition of ozone over a boreal pine forest, Atmos. Chem. Phys., 9, 2089-2095, doi:10.5194/acp-92089-2009, 2009.

Rinne, J., Taipale, R., Markkanen, T., Ruuskanen, T. M., Hellén, H., Kajos, M. K., Vesala, T., and Kulmala, M.: Hydrocarbon fluxes above a Scots pine forest canopy: measurements and modeling, Atmos. Chem. Phys., 7, 3361-3372, doi:10.5194/acp-73361-2007, 2007.

Rinne, J., Markkanen, T., Ruuskanen, T. M., Petäjä, T., Keronen, P., Tang, M. J., Crowley, J. N., Rannik, Ü., and Vesala, T.: Effect of chemical degradation on fluxes of reactive compounds - a study 
with a stochastic Lagrangian transport model, Atmos. Chem. Phys., 12, 4843-4854, doi:10.5194/acp-12-4843-2012, 2012.

Slinn, W. G. N.: Prediction for particle deposition tovegetative canopies, Atmos. Environ., 16, 1785-1794, 1982.

Stella, P., Personne, E., Loubet, B., Lamaud, E., Ceschia, E., Béziat, P., Bonnefond, J. M., Irvine, M., Keravec, P., Mascher, N., and Cellier, P.: Predicting and partitioning ozone fluxes to maize crops from sowing to harvest: the Surfatm- $\mathrm{O}_{3}$ model, Biogeosciences, 8, 2869-2886, doi:10.5194/bg-8-2869-2011, 2011.

Stroud, C., Makar, P., Karl, T., Guenther, A., Geron, C., Turnispeed, A., Nemitz, E., Baker, B., Potosnak, M.m and Fuentes, J.D.: Role of canopy-scale photochemistry in modifying biogenicatmosphere exchange of reactive terpene species: Results from CELTIC field study, J. Geophys. Res., Vol. 110, D173030, doi:10.1029/2005JD005775, 2005.

Taipale, R., Ruuskanen, T. M., Rinne, J., Kajos, M. K., Hakola, H., Pohja, T., and Kulmala, M.: Technical Note: Quantitative long-term measurements of VOC concentrations by PTR-MS measurement, calibration, and volume mixing ratio calculation methods, Atmos. Chem. Phys., 8, 6681-6698, doi:10.5194/acp8-6681-2008, 2008.

Tarvainen, V., Hakola, H., Hellén, H., Bäck, J., Hari, P., and Kulmala, M.: Temperature and light dependence of the VOC emissions of Scots pine, Atmos. Chem. Phys., 5, 989-998, doi:10.5194/acp-5-989-2005, 2005.

Thum, T., Aalto, T., Laurila, T., Aurela, M., Kolari, P., and Hari, P.: Parametrization of two photosynthesis models at the canopy scale in a northern boreal Scots pine forest, Tellus, 59B, 874890, 2007.

Turnipseed, A. A., Burns, S. P., Moore, D. J. P., Hu, J., Guenther, A. B., and Monson, R. K.: Controls over ozone deposition to a high elevation subalpine forest, Agr. Forest Meteorol., 149, 1447-1459, 2009.
Valentini, R., Matteucci, G., Dolman, A. J., Schulze, E. D., Rebmann, C., Moors, E. J., Granier, A., Gross, P., Jensen, N. O., Pilegaard, K., Lindroth, A., Grelle, A., Bernhofer, C., Grünwald, T., Aubinet, M., Ceulemans, R., Kowalski, Kowalski, A. S., Vesala, T., Rannik, Ü., Berbigier, P., Lousteau, D., Guðmundsson, J., Thorgeirsson, H., Ibrom, A., Morgenstern, K., Clement, R., Moncrieff, J. B., Montagnani, L., Minerbi, S., and Jarvis, P. G.: Respiration as the main determinant of carbon balance in European forests, Nature, 404, 861-865, 2000.

Vesala, T., Suni, T., Rannik, Ü., Keronen, P., Markkanen, T., Sevanto, S., Kulmala, M., Uotila, A., Kolari, P., Berninger, F., Ilvesniemi, H., Nikinmaa, E., and Hari, P.: Effect of thinning on surface fluxes in a boreal forest, Global Biogeochem. Cy., 19, GB2001, doi:10.1029/2004GB002316, 2005.

Vickers, D. and Mahrt, L.: Quality control and flux sampling problems for tower and aircraft data, J. Atmos. Ocean. Tech., 14, 512 527, 1997.

Walton, S., Gallagher, M. W., and Duyzer, J. H.: Use of a detailed model to study the exchange of $\mathrm{NO}_{\mathrm{x}}$ and $\mathrm{O}_{3}$ above and below a deciduous canopy, Atmos. Environ., 31, 2915-2931, 1997.

Wesely, M. L. and Hicks, B. B.: A review of the current status of knowledge on dry deposition, Atmos. Environ., 34, 2261-2282, 2000.

Zhang, L., Brook, J. R., and Vet, R.: On ozone dry deposition with emphasis on nonstomatal uptake and wet canopies, Atmos. Environ., 36, 4787-4799, 2002. 